Cómo citar este artículo: Torrijos, V. \& Abella, J. D. (2017, julio-diciembre). Ventajas y desventajas políticas y militares para Colombia derivadas de su eventual participación en misiones internacionales relacionadas con la OTAN. Rev. Cient. Gen. José María Córdova, 15(20), 47-82. DOI: http://dx.doi.org/10.21830/19006586.175

\title{
Ventajas y desventajas políticas y militares para Colombia derivadas de su eventual participación en misiones internacionales relacionadas con la OTAN*
}

DOI: http://dx.doi.org/10.21830/19006586.175

Recibido: 31 de mayo de 2016 • Aceptado: 5 de junio de 2017

Political and Military Advantages and Disadvantages for Colombia Deriving from its Eventual Participation in International Missions Related to NATO

Avantages et des désavantages politiques et militaires pour la Colombie découlant de sa participation éventuelle aux missions internationales liées à l'OTAN

Vantagens e desvantagens políticas e militares para a Colômbia, derivadas de sua eventual participação em missões internacionais relacionadas com a OTAN

\author{
Vicente Torrijos ${ }^{a}$ \\ Juan David Abella ${ }^{b}$
}

* Artículo resultado del proyecto de investigación No col 0025 289, titulado "Tendencias Evolutivas del Terrorismo en Colombia: Las FARC 2010-2019”, vinculado al Centro de Estudios Políticos e Internacionales de la Universidad del Rosario.

a Universidad del Rosario, Bogotá, Colombia. Doctorado en Relaciones Internacionales y posdoctorado en Asuntos Estratégicos, Seguridad y Defensa. <vicentetorrijos@hotmail.com>.

b Universidad del Rosario, Bogotá, Colombia. Politólogo candidato a magíster en Construcción de Paz de la Universidad de los Andes. <juan.abella@urosario.edu.co>. 
Resumen. La Política de Defensa y Seguridad para la Nueva Colombia 2015-2018 se ha fijado como meta la búsqueda de alianzas y acercamientos internacionales para posicionar a Colombia como un líder en temas de la defensa y seguridad, primero a nivel hemisférico, y posteriormente a nivel global. Para lograr dicha meta, el Gobierno nacional ha considerado la participación activa del Estado en las Misiones Internacionales relacionadas con la Organización del Tratado del Atlántico Norte (OTAN). Fijando su atención en este último escenario, el presente artículo desarrolla una reflexión integral y analítica no solo del funcionamiento, la evolución, los logros y los desafíos de tales misiones, sino que también hace un examen profundo de las relaciones entre Colombia y la OTAN, así como de las posibles ventajas y desventajas de índole político y militar derivadas de una eventual participación del Estado colombiano en las Misiones Internacionales de la organización atlántica.

Palabras clave: Colombia; defensa; misiones internacionales; OTAN; seguridad.

Abstract. The Defense and Security Policy for the New Colombia 2015-2018 has set the goal to seek alliances and international approaches in order to position Colombia as a leader in issues of defense and security at a hemispheric and global level. In order to achieve this goal the Government has considered the active participation of the State within the International Missions related to the North Atlantic Treaty Organization (NATO). Placing the attention on this last scenario, this article aims to develop a comprehensive and analytical reflection not only over the performance, the evolution, the achievements and the challenges of such missions; also it aims to make a deep exam about the Colombia-NATO relations, and the possible political and military advantages and disadvantages from a possible participation of the Colombian State inside the North Atlantic Alliance International Missions.

Keywords: Colombia; defense; International Missions; NATO; security.

Résumé. La politique de la défense et la sécurité pour la nouvelle Colombie 2015-2018 a fixé comme objectif la recherche des alliances et internationales approches afin de positionner la Colombie comme un leader dans les questions de défense et de sécurité à un niveau continental et mondial. Pour obtenir cet objectif, le Gouvernement a examiné la participation active de L'État dans les Missions Internationales lié à l'Organisation du Traité de l'Atlantique Nord (OTAN). En accordant une attention sur ce dernier scénario, cet article vise à développer une réflexion globale et analytique non seulement sur la performance, l'évolution, les réalisations et les défis de ces missions; il vise également à faire un profond examen sur les relations Colombie-OTAN, et les avantages et inconvénients politiques et militaires possibles d'une éventuelle participation de L'État colombien dans les missions de l'alliance de l'Atlantique Nord.

Mots-clés: Colombie; défense; sécurité; Missions Internationales; NATO.

Resumo. A Política de Segurança e Defesa pela Nova Colômbia 2015-2018 estabeleceu uma meta de buscar alianças e abordagens internacionais para posicionar a Colômbia como um líder em questóes de defesa e segurança, a nível hemisférico e a nível mundial. Para atingir este objetivo, o Governo considerou a participação ativa do Estado no âmbito de Missōes Internacionais relacionadas com o NATO. Fixando sua atenção no último cenário, este artigo tem como objetivo desenvolver uma reflexão abrangente e analítica, não só do funcionamento, desenvolvimento, realizaçóes e desafios de tais $\mathrm{MI}$; e ainda fazer um profundo exame acerca as relaçôes Colômbia-NATO e das possíveis vantagens e desvantagens de natureza política e militar decorrentes de uma eventual participação do Estado colombiano nas missôes internacionais da NATO.

Palavras chave: Colômbia; defesa; Missóes Internacionais; NATO; segurança. 


\section{Introducción}

El presente escrito se genera como producto del gran interés que han suscitado las ambiciosas metas fijadas en la Política de Defensa y Seguridad para la Nueva Colombia 2015-2018 en materia de diplomacia de seguridad y defensa. Específicamente, dicha política ha establecido el deseo del Estado colombiano en posicionarse como un líder en temas de la defensa y la seguridad, primero en el hemisferio, y posteriormente a nivel global.

Para conseguir esto, el Gobierno no solo le ha encargado al segmento de la diplomacia de seguridad y defensa la búsqueda de alianzas y acercamientos estratégicos, sino que también ha procurado que el país se involucre en las llamadas Misiones Internacionales, cuyo objetivo es prestar ayuda humanitaria o restablecer las instituciones básicas tras la ocurrencia de desastres naturales o de conflictos de índole social, política y/o económica. Al respecto de tales acercamientos, se ha generado en los últimos años un debate interesante, pero no siempre muy elaborado ni exigente, frente a los elementos positivos y negativos de la participación efectiva de Colombia en las Misiones Internacionales asociadas con la Organización del Tratado del Atlántico Norte (OTAN).

Con el objetivo de abordar dichas temáticas de manera teórica y analítica, y así aportar luces e ideas razonadas a la discusión permanente, el presente artículo pretende desarrollar una reflexión integral y analítica no solo del funcionamiento, la evolución, los logros y los desafíos de tales Misiones Internacionales, sino que también hace un examen profundo frente a las relaciones entre Colombia y la OTAN, así como de las posibles ventajas y desventajas de índole político y militar derivadas de una eventual participación del Estado colombiano en las Misiones Internacionales del organismo.

Para conseguir esto último, el documento se divide en cuatro partes interconectadas, por medio de las cuales se abordarán distintas dimensiones y elementos de la cuestión mencionada, priorizando la exposición de casos y ejemplos fácticos concretos. Al respecto, en la primera parte se realiza un análisis del funcionamiento de la OTAN en las Misiones Internacionales, incluyendo la evolución del Concepto Estratégico de la Organización, los principales logros producto de tales misiones, los desafíos modernos que enfrentan estas intervenciones extranjeras, y además una revisión breve del recorrido de las relaciones entre Colombia y la Alianza Atlántica.

En la segunda y tercera parte se hace un análisis tanto de las ventajas para Colombia derivadas de su participación (actual y eventual) en Misiones Internacionales de naturaleza militar (o relacionadas con seguridad y defensa), como de las ventajas para Colombia derivadas de su participación (actual y eventual) en Misiones Internacionales de naturaleza política (o relacionadas con la democracia).

En la cuarta y quinta secciones, el artículo trata la compleja cuestión de las posibles desventajas para Colombia derivadas de su eventual participación en Misiones Internacionales, tanto de naturaleza militar como política, para lo cual se presta especial atención en la experiencia de otros países, como son los casos de Chile y Argentina.

Finalmente, y teniendo en cuenta los hallazgos y las comparaciones permitidas tras el desarrollo de las secciones anteriores, el artículo presenta tres conclusiones puntuales que dan cuenta no solo del valor estratégico singular de la organización atlántica, sino también de los productos 
de la no siempre homogénea relación entre Colombia y la OTAN. El balance de tales productos deja como gran lección la necesidad de que Colombia explore caminos para que su participación e involucramiento se traduzca, cada vez más, en una mayor generación y obtención de recursos genuinos de construcción de paz (útiles tanto en el exterior como en el interior), de manera que esto contribuya en doble vía tanto en sus metas de posicionamiento internacional como en la atención a sus desafíos de seguridad y desarrollo domésticos.

\section{Análisis del funcionamiento de la OTAN en misiones internacionales}

La llamada Organización del Tratado del Atlántico Norte tiene sus orígenes en la firma del Tratado de Washington de 1949, por medio del cual doce países localizados en el sector norte de los dos lados del océano Atlántico (Bélgica, Canadá, Dinamarca, Estados Unidos, Francia, Islandia, Italia, Luxemburgo, Noruega, Países Bajos, Portugal y Reino Unido) decidieron suscribir un compromiso de defensa mutua y coordinada en caso de presentarse algún tipo de agresión armada contra cualquiera de ellos (Ministerio de Asuntos Exteriores y Cooperación de Espańa, 2015).

Este tipo de acuerdo, que vinculaba la defensa de América del Norte con un conjunto de países de Europa Occidental, nace bajo el sustento del Capítulo VII de la Carta de las Naciones Unidas, el cual reconoce en su Artículo 51 que

[n]inguna disposición de esta Carta menoscabará el derecho inmanente de legítima defensa, individual o colectiva, en caso de ataque armado contra un Miembro de las Naciones Unidas, hasta tanto que el Consejo de Seguridad haya tomado las medidas necesarias para mantener la paz y la seguridad internacionales. Las medidas tomadas por los Miembros en ejercicio del derecho de legítima defensa [...] no afectarán en manera alguna la autoridad y responsabilidad del Consejo conforme a la presente Carta para ejercer en cualquier momento la acción que estime necesaria con el fin de mantener o restablecer la paz y la seguridad internacionales. (Naciones Unidas, 1945)

A pesar de que el mismo dinamismo y la evolución de la situación del sistema internacional ha contribuido a determinar, en gran medida, la continua adaptación de la Alianza Atlántica a los cambios en su entorno estratégico, la Organización ha guiado su operación en torno a cuatro elementos o puntos básicos transversales a lo largo de sus ya 67 años de existencia: $i$ ) un vínculo de tipo político y militar; ii) la defensa colectiva como fundamento supremo; iii) el lazo transatlántico como rasgo identitario; y iv) el compromiso y ajuste al denominado Concepto Estratégico ${ }^{1}$ (North Atlantic Treaty Organization [NATO], 2016).

Estos cuatro elementos han definido y definen la actuación interna y externa de la Organización, y por tanto constituyen un elemento esencial a la hora de aproximarse al accionar de la Alianza en el marco de las llamadas Misiones Internacionales, entendidas de manera amplia como todas aquellas actividades, limitadas a una dimensión temporal y geográfica concreta, por medio de las cuales distintos actores del sistema internacional dirigen sus esfuerzos a atender una

1 Traducción libre de los autores. 
problemática o desafío que vulnere la integridad y la dignidad humanas, y por tanto constituyan una amenaza creíble a la paz y la seguridad internacional (NATO, 1949).

Un aspecto fundamental en el estudio del funcionamiento de la OTAN en las Misiones Internacionales es, precisamente, el carácter colectivo que identifica a la misma Organización. Este carácter se ve reflejado en el hecho de que las decisiones finales sobre el actuar se toman por consenso y son adoptadas por el Consejo Atlántico, la autoridad suprema de la Alianza compuesta por los representantes de los 28 países aliados con embajadores permanentes, o por los ministros (de Defensa y/o Exteriores) o jefes de Estado o de gobierno que se reúnen con carácter periódico o extraordinario (cada dos años en el caso de los jefes de Estado) (Blasco, 2014). Esto quiere decir que cualquier decisión sobre el involucramiento y esfuerzo de la OTAN en Misiones Internacionales debe ser analizada y aprobada por todos sus miembros, un hecho que no siempre ha estado exento de polémica ${ }^{2}$.

Como ya se mencionaba, la evolución de los fenómenos y los desafíos a nivel internacional ha generado una reacción cada vez más compleja de la OTAN, lo cual era de esperarse dado su carácter de organización en gestión de crisis, con una capacidad casi única en el mundo de llevar a cabo una amplia gama de operaciones militares y Misiones Internacionales. Como se verá posteriormente, el funcionamiento de la OTAN en estas misiones no se reduce a aspectos defensivos o disuasorios, y usualmente el involucramiento y los condicionamientos de la operación de la OTAN están precedidos y definidos por alguna Resolución del Consejo de Seguridad de la ONU o por una solicitud tanto de Estados miembros como de Estados externos.

\section{Evolución y tendencias recientes}

El funcionamiento y la doctrina de operación de la organización atlántica ha sufrido, a lo largo de sus años de existencia, una serie de cambios sustanciales, los cuales se pueden organizar en torno a tres grandes transformaciones del Concepto Estratégico ${ }^{3}$ de la OTAN —entendido como un ejercicio orientado a guiar el planeamiento práctico-, sucedidos con motivo de sus Cumbres periódicas, y en contextos de cambios profundos en las dinámicas del sistema internacional (Arteaga, 2010, p. 2). La tabla 1 constituye un esfuerzo por abordar y describir cada uno de estos tres planteamientos estratégicos clave, hasta su versión más reciente a la fecha.

2 En 2003, durante una reunión informal que sostuvieron los ministros de Defensa aliados, salieron a relucir varias de las inquietudes y los desacuerdos frente al sistema de toma de decisión de la OTAN. El objetivo de la reunión fue discutir caminos para desarrollar este tipo de procesos de forma más ágil, teniendo en cuenta las experiencias recientes, como el bloqueo de Francia, Alemania y Bélgica por solicitud de los EE. UU. al entender que ello precipitaba una guerra inevitable contra Irak; o cuando después de largas disertaciones, 18 de los 19 aliados (todos menos Francia) aprobaron prestar ayuda a Ankara, pero el Parlamento turco decidió votar en contra del paso de soldados norteamericanos por su territorio (Esteruelas, 2003).

3 Los aliados definen las misiones y objetivos de la OTAN por medio de un Concepto Estratégico aprobado por el Consejo al nivel de los jefes de Estado y de gobierno de los Estados miembros. Este documento describe el entorno de seguridad de la Organización, las amenazas por enfrentar y las funciones que le son asignadas. El Concepto también establece las directrices que guiarán la adaptación de las herramientas e instrumentos militares de los aliados para estas misiones. Es de destacarse que la OTAN ha contado con aproximadamente nueve Conceptos Estratégicos en el curso de su existencia, y desde 1991 estos documentos son de conocimiento público, aunque se siguen manteniendo clasificados los documentos de desarrollo (Arteaga, 2010, pp. 3-4; Permanent Representation of France to NATO, 2013). 
Tabla 1. Conceptos estratégicos de la OTAN, 1991-2010

\begin{tabular}{cc}
\hline $\begin{array}{c}\text { Concepto } \\
\text { Estratégico }\end{array}$ & Contexto global \\
\hline & - Cumbre de Roma de 1991. \\
& - Desvanecimiento de una amenaza de \\
& invasión militar proveniente del enemi- \\
& go soviético, que sería sustituida por los \\
& riesgos que generan las incertidumbres \\
& sobre el Viejo Continente.
\end{tabular}

1991

- Cumbre de Washington de 1999.

- Se afirma que la OTAN ha logrado asegurar con éxito la libertad de sus miembros y ha prevenido una nueva guerra en Europa durante los cuarenta años de la Guerra Fría. Los aliados reconocen que la combinación de la defensa con el diálogo ha desempeñado un papel imprescindible para llevar la confrontación Este-Oeste a un final pacífico.

- Ampliación de la Organización hacia países de Europa del Este (Polonia, Hungría y República Checa). Se deja además la puerta abierta a otros posibles miembros en el futuro.

1999

- Mejora del escenario estratégico en razón a que la amenaza de destrucción masiva y generalizada ha desaparecido, pero aparecen nuevos riesgos.
- Riesgo residual en virtud de la subsistencia de armas atómicas en una URSS en ruta hacia el desmoronamiento. De cualquier forma, los aliados han convenido contemplar la utilización de armas nucleares como último recurso.

- Riesgo de ebullición en Europa Oriental a causa del auge de los nacionalismos y el temor de las llamadas "Democracias huérfanas" a que se vulnere su soberanía y sus fronteras.

- Riesgo de alta inestabilidad en zonas periféricas del ámbito geográfico atlántico, empezando por el Mediterráneo árabe, sin que esto signifique un acuerdo por extender el marco de actuación de la OTAN.

- Gran similitud con los riesgos identificados desde 1991.

- Las descripciones de los retos y riesgos de seguridad fueron genéricas, no se vincularon con alguna identidad en concreto, tampoco hubo una organización de riesgos según prioridades ni se incluyeron las vulnerabilidades que ya revelaba la Organización frente a las demandas y expectativas en el Este europeo y en las periferias.

- La seguridad e integridad de los Estados miembro sigue siendo un elemento de preocupación frente a las amenazas asimétricas.

- Las crisis no de tipo militar sino de tipo humanitario, ambiental y ecológico comienzan a tener eco en la cuestión de gestión y manejo de la OTAN.

\section{Rutas de acción establecidas}

- Establecimiento de nuevas formas de cooperación política y militar para tratar los conflictos regionales y preservar la paz y la estabilidad, principalmente con las repúblicas bálticas y los países del Este.

- Planteamiento amplio sobre seguridad, basado en el diálogo, la cooperación y el mantenimiento de una capacidad de defensa colectiva.

- Cooperación con antiguos adversarios.

- Gestión de crisis.

- Fin de la defensa clásica.

- Fuerzas más reducidas, pero de mayor disponibilidad.

- Mayor flexibilidad de la línea de mando y de movilidad de las unidades militares.

- Las Misiones de las fuerzas aliadas son similares a las establecidas en 1991.

- La Organización redirige su espacio geográfico de actuación, desde el ámbito europeo al euroatlántico, al que se circunscribió la gestión de crisis y el partenariado.

- Gestión de crisis e incremento de la asociación y el diálogo con otros países del área euroatlántica, que tenían como objeto incrementar la transparencia, la confianza mutua y la acción conjunta.

- Asesorar en las nuevas tareas de seguridad.

- Profundización de actividades relacionadas con el control de armamento, el desarme, la no proliferación, el asociacionismo (partnership), la cooperación y el diálogo.

- Asegurar un espacio euroatlántico estable y seguro.

- Establecer las consultas necesarias para la resolución pacífica de las disputas.

- Disuasión y defensa frente a cualquier amenaza de agresión contra cualquier Estado miembro.

- Prevención de conflictos, gestión de crisis y Asociación para la Paz. 


\begin{tabular}{|c|c|c|c|}
\hline $\begin{array}{l}\text { Concepto } \\
\text { Estratégico }\end{array}$ & Contexto global & Riesgos identificados & Rutas de acción establecidas \\
\hline 2010 & $\begin{array}{l}\text { - Cumbre de Lisboa y Cumbre de Chicago } \\
\text { de } 2012 . \\
\text { - Desdibujamiento del perfil de la OTAN } \\
\text { como organización regional de defensa, } \\
\text { hacia un régimen de seguridad global. } \\
\text { - Persiste el debate sobre la ampliación, } \\
\text { tanto de miembros como de capaci- } \\
\text { dades, fuera del perímetro tradicional } \\
\text { para incluir a países como Japón o una } \\
\text { mayor participación en el Gran Oriente } \\
\text { Medio. Sin embargo, se debe admitir } \\
\text { que la OTAN sigue siendo una alianza } \\
\text { euroamericana o euroatlántica, cuyos } \\
\text { socios se han ido ampliando por la par- } \\
\text { te europea sin salir nunca del perímetro } \\
\text { de Europa. } \\
\text { - Funcionalmente, la OTAN se ha con- } \\
\text { vertido en una alianza global y está lista } \\
\text { para actuar a escala mundial. } \\
\text { - Los atentados terroristas del } 11 \text { de sep- } \\
\text { tiembre de } 2001 \text { en EE. UU., del } 11 \text { de } \\
\text { marzo de } 2004 \text { en Madrid y del } 7 \text { de } \\
\text { julio de } 2005 \text { en Londres representaron } \\
\text { un importante punto de partida para } \\
\text { entender la estrategia de actuación de la } \\
\text { OTAN en los próximos años. } \\
\text { - La Alianza se prepara para afrontar los } \\
\text { nuevos retos globales del siglo XXI, } \\
\text { como el terrorismo, la proliferación nu- } \\
\text { clear o los ciberatagues. }\end{array}$ & $\begin{array}{l}\text { - Terrorismo global, más sofisticado y } \\
\text { adaptativo. } \\
\text { - Proliferación nuclear. } \\
\text { - Ciberataques y vulneración de infraes- } \\
\text { tructura vital de difícil rastreo. } \\
\text { - En la Cumbre de Lisboa los aliados } \\
\text { reconocen que la inestabilidad de los } \\
\text { conflictos, más allá de las fronteras de la } \\
\text { OTAN, puede amenazar directamente } \\
\text { a la seguridad de la Organización. } \\
\text { - Misiles de largo alcance y capacidades } \\
\text { militares en manos de actores subversi- } \\
\text { vos del orden y la seguridad. } \\
\text { - Alta vulnerabilidad en cuanto a seguri- } \\
\text { dad energética. } \\
\text { - Inquietudes ante una política exterior } \\
\text { rusa más ofensiva y ambiciosa. }\end{array}$ & $\begin{array}{l}\text { - Desarrollo de capacidades tanto para } \\
\text { los aliados más vulnerables como en } \\
\text { sus zonas de misión y operación inter- } \\
\text { nacionales. } \\
\text { - Atención integral y urgente a la situa- } \\
\text { ción de Afganistán. } \\
\text { - Diseńo de un único marco político para } \\
\text { establecer relaciones recíprocas con } \\
\text { terceros Estados. Se decide priorizar la } \\
\text { formación de "asociaciones" como prin- } \\
\text { cipal instrumento de la OTAN para lle- } \\
\text { var a cabo su cooperación externa. } \\
\text { - Intención de multiplicar estas asocia- } \\
\text { ciones por todo el globo, una tendencia } \\
\text { a la multiplicación que ciertamente está } \\
\text { ya en marcha. } \\
\text { - Prioridad en fuerzas de respuesta rápi- } \\
\text { da, racionalización de medios, mejora } \\
\text { de la eficacia, ahorro financiero y flexi- } \\
\text { bilidad en la estructura de mandos. } \\
\text { - Pasar de una política de estabilidad, } \\
\text { acompañada de una retórica de demo- } \\
\text { cracia, a una política más concreta y } \\
\text { objetiva de reformas y democratización, } \\
\text { con la que se actué en favor de las re- } \\
\text { formas y la buena gobernanza con sus } \\
\text { socios externos. }\end{array}$ \\
\hline
\end{tabular}

Fuente: elaboración de los autores con base en la información de Aliboni (2011), Arteaga (2010), Cembrero (1991), Conde (2000), Martín (2010), Martínez (2010) y NATO (1999).

\section{Logros de las misiones internacionales de la OTAN}

Como se ha mencionado, al constituir una organización en gestión de crisis, la OTAN tiene la capacidad de llevar a cabo una amplia gama de operaciones militares y de misiones internacionales, las cuales se han complejizado notablemente desde principios de 1990 (NATO, 2015a).

En la actualidad, la Organización cuenta con más de dieciocho mil efectivos militares involucrados en misiones internacionales de tipo terrestre, aérea y naval en todo el mundo, incluyendo teatros de operación en Afganistán, Kosovo, el Mediterráneo y el Cuerno de África, y la realización de operaciones de vigilancia aérea, de socorro y de protección de la población frente a desastres naturales, tecnológicos o humanitarios (NATO, 2015a). 
La tabla 2 es un esfuerzo por resumir y organizar esta gama de actividades (junto con sus características e impactos) en tres grandes conjuntos: operaciones típicas de Guerra Fría; operaciones post-Guerra Fría terminadas, y, finalmente, operaciones contemporáneas activas:

Tabla 2. Tipología de las misiones internacionales y las operaciones militares de la OTAN

Misiones internacionales y operaciones militares de Guerra Fría (1949 -1990)

Operación Anchor Guard 1991

Operación Ace Guard 1991

Operación Agile Genie 1992
- Tras la invasión iraquí a Kuwait en 1990, el equipo aéreo de la OTAN fue desplegado en Turquía con el fin de monitorear la crisis y recabar información sobre posibles amenazas para ese país.

- La solicitud turca fue respondida de manera adecuada con la entrada en operación de siete aviones y personal de apoyo, los cuales brindaron una cobertura de vigilancia 24 horas al día hasta cuando se decretó el cese al fuego en el conflicto en Iraq.

- Se cita como logro de la operación el incidente de un avión de combate turco que se perdió en el espacio aéreo iraquí y que fue escoltado y guiado de nuevo a espacio aéreo turco por parte de las aeronaves dispuestas por la OTAN en la zona.

- En respuesta a una solicitud turca de asistencia, la OTAN desplegó la Fuerza Aérea Móvil ACE y otorgó a Turquía un paquete de medidas de defensa aérea.

- Los aliados volvieron a responder oportunamente a la solicitud turca durante la Segunda Guerra del Golfo, con el envío de más de diez aeronaves alemanas, belgas e italianas, las cuales proporcionaron cobertura y defensa al territorio turco sin involucrarse en el conflicto en Iraq. Al contingente se ańadieron cientos de soldados, dos helicópteros de combate, varios vehículos de reconocimiento, sistemas de misiles de defensa aérea, personal técnico de apoyo, entre otros.

- Las tensiones entre Occidente y Libia tras la imposición de sanciones autorizadas por el Consejo de Seguridad con el fin de presionar al país africano tras los incidentes de Lockerbie, llevaron a la OTAN a proveer, con aeronaves AWACS, una actividad de monitoreo sobre las rutas en el litoral de la costa mediterránea africana.

- Tras la imposición de sanciones de parte del Consejo de Seguridad de la ONU a Libia, la OTAN acata su mandato de realizar operaciones de vigilancia aérea a lo largo de la costa libia por medio del envío de aviones AWACS. En esta operación se destaca la oportuna participación de Noruega, con la contribución de personal calificado para el funcionamiento de las fuerzas AWACS desplegadas por la OTAN. 
Fuerza Internacional de Asistencia para la Seguridad en Afganistán (ISAF)

\section{OTAN en Bosnia y Herzegovina}

\section{OTAN en la República Yugoslava de Macedonia}

\section{Segunda Guerra del Golfo}

\author{
Protección \\ de eventos públicos
}

- El objetivo era desarrollar las nuevas fuerzas de seguridad afganas y capacitar a las autoridades en la provisión de seguridad efectiva a lo largo del país, con el fin de crear un ambiente que condujera al funcionamiento de las instituciones democráticas.

- La OTAN realizó una misión de trece años, tiempo en el cual tuvo bajo su responsabilidad el control y la dirección de miles de tropas, principalmente en el Este del país. En la Cumbre de Lisboa, los aliados decidieron establecer un calendario de retirada que finalizó en el año 2014, reemplazando la misión de combate con una tarea de asesoramiento y un pequeńo contingente de tropas extranjeras ante un contexto de violencia creciente.

- Quedarán en el país 10.800 soldados estadounidenses y entre 3.000 y 4.000 militares de la OTAN. En 2014, los talibanes calificaron esta retirada como una victoria a su favor contra los invasores.

- Operaciones militares de imposición y mantenimiento de paz por medio de IFOR y de SFOR. Concluye con la intervención de la UE y la implementación de la Operación Althea. La OTAN mantiene un cuartel militar en el país encargado de tareas relacionadas con asistencia a las instituciones de gobierno y la reforma en sus estructuras de defensa.

- Desarrollo de las Operaciones Essential Harvest, Amber Fox y Allied Harmony. La actividad de la organización se centró en tres tareas específicas:

1. Desarme de los grupos étnicos albaneses operativos en el país.

2.Protección a los observadores internacionales que supervisan la implementación del plan de paz.

3. Provisión de asesoría y asistencia al gobierno con el fin de asegurar la estabilidad en todo el país.

- Operación Display Deterrence: la OTAN desplegó aviones con radar AWACS y baterías antiaéreas con el fin de fortalecer la defensa de Turquía frente a posibles amenazas del conflicto.

- La operación comenzó el 20 de febrero, se prolongó hasta el 16 de abril de 2003. Los aviones realizaron 100 misiones con un total de 950 horas de vuelo.

- Operación Distinguished Games en Grecia y el desarrollo del esquema de seguridad integral en la Cumbre de Riga. 
Misiones internacionales y operaciones post-Guerra Fría terminadas (siglo XXI)

\section{Protección de eventos públicos}

\section{Huracán Katrina}

\section{Asistencia tras el terremoto de Pakistán}

\section{Asistencia a la Unión Africana en Darfur}

Operaciones contra la piratería en el Golfo de Adén y el Cuerno de África
- Específicamente, la OTAN asistió al gobierno griego proporcionando apoyo en materia de inteligencia, suministrando recursos de defensa de tipo químico, radiológico, biológico y nuclear, aviones con radar AWACS. Al mismo tiempo, la OTAN también respondió positivamente a una solicitud de Letonia, proporcionando seguridad técnica, capacidades de respuesta de tipo aéreo, naval y de policía, sistemas de detección de artefactos explosivos improvisados, soporte de comunicación y sistemas de información, y recursos de apoyo para la atención médica.

- Plan militar dirigido a asistir a EE. UU., que consistía en ayudar a coordinar el transporte de material de urgencia y apoyar los esfuerzos de ayuda humanitaria.

- Esta fue una de las iniciativas humanitarias más grandes desarrolladas por la OTAN. Posteriormente la Organización participaría en actividades similares en Turquía, Ucrania y Portugal. La experiencia acumulada y las crecientes necesidades de contar con capacidades adecuadas llevaron a la constitución de un Centro Euro-Atlántico de Respuesta de Desastres.

- La OTAN prestó soporte logístico a la Misión de la Unión Africana en Sudán (AMIS) por medio de transporte aéreo y entrenamiento de personal. Una vez finalizada su actividad, la Organización manifestó su interés en seguir apoyando la nueva misión de mantenimiento de paz (UNAMID, por su sigla en inglés).

- La Operación Allied Provider de la OTAN se enfocó en el desarrollo de tres objetivos principales:

1. Escoltar los buques del Programa Mundial de Alimentos (WFP, por su sigla en inglés)

2. Escoltar los buques de la Unión Africana destinados a sus contingentes en Burundí.

3. Mejora de la seguridad para la actividad comercial por medio de la protección de las rutas marítimas.

Misiones internacionales y operaciones vigentes en el siglo XXI

OTAN en Afganistán en 2015

- Afganistán es uno de los escenarios de mayor actividad de la OTAN, en el cual implementa las siguientes actividades:

1. Misión Resolute Support con la cual se provee de entrenamiento, asesoría y asistencia a las fuerzas afganas de seguridad.

2. ISAF, una fuerza internacional encargada de prevenir que el país se transforme nuevamente en un refugio de terroristas por medio de la provisión de seguridad efectiva que asegure la existencia del Estado de Derecho en todo el territorio y el buen funcionamiento de las instituciones estatales. 


\section{Misiones internacionales y operaciones vigentes en el siglo XXI}

\section{OTAN en Kosovo}

\section{Monitoreo del Mar Mediterráneo}

\section{Apoyo a la Unión Africana}

Misiones de vigilancia aérea
- Por medio de las Kosovo Forces (KFOR), las fuerzas aliadas cuentan con más de cuatro mil tropas operando en Kosovo encargadas de preservar la paz que había sido impuesta por la OTAN hace más de quince años.

- Estas unidades también tienen el deber de ayudar en la creación y consolidación de unas fuerzas de seguridad profesional y multiétnicas en Kosovo, ligeramente armadas y preparadas para tareas que son inadecuadas para la policía.

- La Operación Active Endeavour se enfoca, desde 2001, en realizar acciones de vigilancia marítima con el fin de detectar y disuadir la actividad terrorista en el Mediterráneo. Desde 2003, la OTAN ha estado deteniendo embarcaciones sospechosas.

- Estas actividades han beneficiado la actividad de navegación en los mares y además han probado ser un instrumento efectivo para asegurar una región estratégica, luchar contra el terrorismo y capacitar a las fuerzas navales de los países cercanos.

- La OTAN está decidida a apoyar a la Unión Africana (AU, por su sigla en inglés) en sus misiones de mantenimiento de paz en el continente africano. Por ejemplo, la Organización ha ayudado a la Misión de la AU en Somalia por medio de la provisión de transporte aéreo para los observadores y sus comitivas.

- Desde la intervención militar ilegal rusa en Ucrania en 2014, la OTAN ha tomado medidas preventivas en favor de sus aliados.

- Entre estas acciones se encuentra el desarrollo de misiones colectivas de detección y seguimiento de violaciones al espacio aéreo implementadas en Albania, en Eslovenia y en la región báltica. Asimismo, la OTAN ha establecido distintas fuerzas de vigilancia marítima en las zonas de tensión, así como un sistema defensivo de misiles balísticos.

Fuente: elaboración de los autores con base en la información de "La UE dobla su finaciación...", (2014), Fuerzas Armadas de Noruega (2015), National Defence and the Canadian Forces (2008) y NATO (2015a).

El estudio detallado de la información de la tabla 2 permite proponer tres grandes conclusiones frente al funcionamiento y desempeño de la OTAN en las Misiones Internacionales. La primera conclusión es que la OTAN ha probado, a lo largo de sus ańos de existencia, no solo una voluntad destacable para responder a las solicitudes de sus socios, sino también ha mostrado una importante capacidad para ajustarse a un ambiente internacional en constante cambio, sin que esto se haya traducido necesariamente en un aumento de los riesgos para la seguridad de sus miembros. Ahora bien, las polémicas entre aliados y el debate frente a los mecanismos de toma de decisión colectiva seguirán presentándose, y es poco probable que su intensidad se vaya a reducir en el futuro cercano, dada la inestabilidad que caracteriza hoy al sistema internacional. 
La segunda conclusión consiste en subrayar la amplia gama de posibilidades de participación e involucramiento que ofrece la OTAN tanto para sus miembros de pleno derecho como para sus socios externos. Como se pudo notar en la tabla 2, las Misiones Internacionales de la Organización no se reducen a un carácter de tipo militar, y de hecho en muchas ocasiones este enfoque ha probado ser inadecuado en la tarea de reconstruir la gobernabilidad de los Estados que han sufrido y sufren cruentos conflictos. La OTAN ha reconocido esta problemática y ha incluido entre su "arsenal" programas y acciones dirigidos a contribuir en la (re)consolidación (o instauración) de las instituciones democráticas y de las fuerzas de seguridad. Este es sin duda un rubro en el que los Estados de la órbita no euroatlántica pueden contribuir, dada su experiencia en los procesos de democratización, como es el caso de los países latinoamericanos.

Finalmente, la tercera conclusión es que la OTAN es y seguirá siendo la única organización con capacidad global, capaz de llevar a cabo misiones y operaciones de distinta índole, en las más diversas condiciones. Esta importante capacidad le otorga a la Organización una experticia invaluable en áreas como la vigilancia, la defensa preventiva y la creación de capacidades locales, lo cual se ha traducido en un importante factor de atracción y de interés para otros Estados en distintas regiones del mundo ${ }^{4}$.

Frente a esto, la cuestión del trato con terceros Estados, que ha sido puesta como prioridad por la Organización, debe ser vista estratégicamente por aquellos gobiernos interesados en asociar a sus Estados de manera más estrecha con la Alianza Atlántica. Al respecto, se pueden tomar como casos de referencia los beneficios, en materia de aprendizaje y capacitación recibidos por las fuerzas de seguridad de los Estados que participaron y que participan con la OTAN en las misiones de monitoreo y vigilancia naval.

\section{Desafíos de las misiones internacionales de la OTAN}

Tomando en consideración los sucesos y los pronunciamientos más recientes, además del conjunto de riesgos identificados en el Concepto Estratégico de 2010, descrito anteriormente, es posible sostener que las Misiones Internacionales de la Alianza se enfrentan a los siguientes tres grandes desafíos en el futuro cercano y el futuro próximo: $i$ ) defensa y reafirmación de la vigencia actual de la Organización; ii) la intervención acertada e integral ante los riesgos de erosión de Estados y gobiernos alrededor del mundo, que además puede fortalecerse con la cooperación con terceros Estados; y, finalmente, iii) responder con altura a las exigencias y altas expectativas de la comunidad internacional ante los retos que impone la crisis humanitaria de los migrantes de Oriente Medio.

En primer lugar, la reafirmación de la vigencia de la OTAN constituye un primer desafío fundamental, en la medida en que somete a discusión la continuidad e identidad misma de una organización que, como se ha podido notar en las líneas anteriores, se ha esforzado por ajustarse

4 Cabe notar que, en el presente, y como evidencia de este factor de atracción, la OTAN ya coopera con numerosos países y organizaciones internacionales con distintos esquemas. Frente a esto se puede citar como ejemplo el Diálogo Mediterráneo de la OTAN, así como los vínculos asociativos existentes entre la Organización tanto con el Consejo de Asociación Euro-Atlántica (EAPC) como con la llamada Iniciativa de Cooperación de Estambul (ICI) (NATO, 2015b). 
y adaptarse a un entorno global altamente dinámico. De acuerdo con la Federació d'ONG per la Pau (2011), entre las múltiples razones que hacen de la OTAN un obstáculo para la paz mundial y explican la necesidad de su disolución están:

1. Es un bloque belicista y agresivo que ha abandonado su carácter defensivo.

2. Impulsa nuevas carreras armamentistas y representa la militarización del planeta.

3. Motiva la proliferación y el peligro de guerras nucleares.

4. Es un claro obstáculo para desarrollar la Carta de las Naciones Unidas y normalizar la cooperación entre Europa, EE.UU. y sus antiguos adversarios (Federació d'ONG per la Pau, 2011).

Adicional a esto, de acuerdo con el columnista, periodista y escritor Pat Buchanan, y el investigador del Centro de Investigación de la Globalización (CRG, por su sigla en inglés), Mahdi Nazemroaya, la existencia y continuidad misma del bloque atlántico no solo ha significado un daño recurrente a las relaciones de amistad entre EE.UU. y Rusia, este último visto como un potencial aliado natural de americanos y europeos frente a cuestiones comerciales y de seguridad - citándose como retos comunes la amenaza terrorista islámica, la inestabilidad de regiones estratégicas en materia energética y el avance de China- (Poor, 2012), sino que también constituye un claro instrumento de defensa de intereses políticos sin vocación o interés en contribuir con un mundo más pacífico y más equitativo ${ }^{5}$ (Cattori, 2013).

El segundo desafío de la OTAN mencionado, esto es, el desarrollo cada vez más urgente de que se implementen intervenciones acertadas e integrales ante los riesgos de erosión de Estados y gobiernos alrededor del mundo, surge como producto de dos grandes cuestiones interrelacionadas entre sí: por una parte, el escepticismo generado tras la desastrosa experiencia de Libia y Afganistán, donde se demostró que una "exitosa” intervención militar no generaba automáticamente un nuevo orden en una región. Por otro, las discusiones de la Cumbre de Gales, en la cual los miembros del bloque atlántico definieron como prioridad (y en parte como resultados de la enseñanza de aquellas situaciones desastrosas) la cooperación con terceros Estados y la reafirmación del papel de la Organización en los procesos de reconstrucción nacional en los países bajo intervención (Barfi, 2014; Dobbins, 2005; Kamp, 2014).

El hecho mismo de que Misiones Internacionales como International Security Assistance Force (ISAF) y KFOR, que contenían algunos componentes de transformación y reconstrucción nacional, sean hoy usualmente asociadas al "nuevo horizonte operativo" de la Alianza (Ruiz, 2005), sumado al desarrollo de una visión estructural en el interior de la Organización que ya ha superado los límites de la lucha contraterrorista, y que ha superpuesto la necesidad de una

5 Como evidencia de esta afirmación y en el marco de una entrevista con la periodista de la Universidad de Friburgo, Silvia Cattori, Nazemroaya sostiene que la guerra de la OTAN en Libia ha provocado una reacción en cadena que está siendo usada por los EE. UU. y sus aliados para controlar una vasta extensión de África y de sus recursos. Como ocurrió en la "primera pelea por África” provocada por una crisis económica en los países industrializados de Europa Occidental, los movimientos de la alianza son parte de planes de control de recursos económicos; de hecho, no es coincidencia que a medida que americanos y europeos se han involucrado más en África, también se ha hablado e insistido frecuentemente con la presencia y expansión de franquicias y grupos apoyados por Al-Qaeda (Cattori, 2013). 
actuación nacional, regional y global frente a los desafíos modernos, permiten reflexionar sobre la importancia que reviste para los aliados la llamada cooperación con terceros Estados.

En pocas palabras, este elemento significaría la intención y vocación de la OTAN, en el presente y en el futuro cercano, de involucrar mucho más activamente a sus socios y aliados localizados fuera de la órbita geografía atlántica, con el fin no solo de combatir las amenazas tradicionales a la seguridad, sino también en el marco de fortalecer y consolidar sus Misiones Internacionales asociadas a la construcción y transformación nacional de Estados que viven hoy o que están en tránsito de superar los deplorables caminos del conflicto y la violencia.

El tercer gran desafío es la necesidad y presión que tiene la Organización en el presente para responder con altura a las exigencias y altas expectativas de la comunidad internacional ante los retos que impone la crisis humanitaria de los migrantes de Oriente Medio. Frente a esta cuestión, es importante mencionar que, al contrario de las críticas de la Federació d'ONG per la Pau, en la que se acusa a la OTAN de definir a la inmigración masiva como una amenaza y una de sus grandes preocupaciones (Federació d'ONG per la Pau, 2011), la Organización tiene capacidades, producto de la experiencia, para atender con relativo éxito cuestiones migratorias.

Al respecto, es posible citar dos importantes casos de colaboración y cooperación de la OTAN con motivo de la afluencia masiva de refugiados venidos de Kosovo en 1999: el Programa Humanitario de Evacuación (HEP, por su sigla en inglés) y el Programa Humanitario de Traslado (HTP, por su sigla en inglés). Según cifras oficiales de la Agencia de la ONU para los Refugiados (ACNUR), mientras que el HEP permitió el traslado y acogida segura de más de 96.000 refugiados en más de 28 países, con el HTP se logró transferir exitosamente a más de 1.400 refugiados desde Macedonia a Albania, y se pudo proveer al mismo tiempo de distintos servicios de emergencia, gracias a los acuerdos de cooperación de la OTAN y de la ACNUR, principalmente. (Alto Comisionado de las Naciones Unidas para los Refugiados [ACNUR], 2011, p. 6; United Nations High Commissioner for Refugees [UNHCR], 1999, p. 345)

Ahora bien, es importante notar que, aunque en términos de magnitud la crisis migratoria y humanitaria en el Mediterráneo y en el Este de Europa solo tiene precedentes en los sucesos de la Segunda Guerra Mundial, las enseńanzas del pasado indican que solo el ejercicio de una cooperación integral entre varios actores del sistema internacional puede, en efecto, contribuir positivamente en la resolución de esta grave problemática regional, que tiene todo el riesgo de convertirse en una grave amenaza mundial para la paz y la seguridad.

Por las razones expuestas, no resulta de ninguna manera extraño que hoy en día la OTAN haya sido requerida por varios Estados europeos para que asuma un papel activo en la crisis humanitaria de los migrantes de Oriente $\mathrm{Medio}^{6}$, y que la ACNUR esté proponiendo distribuir equitativamente la responsabilidad, de manera que al menos "el 10\% de los refugiados sirios sean distribuidos y admitidos en todo el mundo, no solo en los Estados miembros, sino también desde América Latina hasta Australia" (ACNUR, 2016; "Acnur propondrá la distribución de refugiados...”, 2016).

6 Por petición de Turquía y Alemania, y como producto de una serie de reuniones de planificación y coordinación, la OTAN ya ha iniciado su intervención con el envío de la agrupación naval permanente número dos en misión en el Mediterráneo hacia el mar Egeo, con el fin de desarrollar labores de vigilancia del tráfico de refugiados. Está planificada la operación plena de tres buques de la OTAN, actualmente bajo comandancia alemana, que trabajarán en cooperación con los guardacostas griegos y turcos, y junto con la Agencia Europea para la Gestión de la Cooperación Operativa en las Fronteras Exteriores de los Estados miembros de la UE (Frontex) (Konstantinidis, 2016). 


\section{Relaciones entre Colombia y la OTAN}

Los acercamientos entre el Estado colombiano y la OTAN datan de 2010, por tanto, no es una iniciativa tan reciente como podría pensarse. Asimismo, tampoco constituye una intención que ha sido particular o exclusiva del Gobierno colombiano, dado que años atrás otros Estados, como Argentina y Chile, han seguido líneas similares, las cuales han suscitado reacciones muy diferentes en los demás países del cono sur americano ${ }^{7}$.

Tomando como referencia la información disponible, proveniente tanto de fuentes oficiales como de los medios de comunicación, es posible aproximarse a una suerte de línea de tiempo de tres etapas, las cuales permiten abordar, entre otras cosas, la evolución y los principales cambios que ha tenido este largo acercamiento entre la OTAN y el Estado colombiano.

La primera etapa, que se denominará como fase exploratoria, inicia en 2006 cuando el gobierno del entonces presidente Álvaro Uribe contempló la posibilidad de que Colombia se convirtiera en socio de la Alianza bajo la categoría de "miembro extra" o aliado "extra-OTAN". Esta iniciativa fue sugerencia informal de parte de los EE. UU., en el marco de un plan que buscaba explorar la conformación de un grupo de países latinoamericanos "amigos" de la organización (García, 2013).

$\mathrm{Al}$ respecto, se destaca la respuesta de la entonces canciller colombiana, Carolina Barco, al ser preguntada en 2006 si el gobierno de los EE. UU., formal o informalmente, había comentado la posibilidad de que Colombia ingresara como miembro en alguna circunstancia de la OTAN: "Estados Unidos ha propuesto que miremos toda nuestra relación y lo que tiene que ver con los distintos aspectos. Esta es una de las posibilidades que se han planteado, pero no es la única [...] en este momento no hay ninguna decisión" (García, 2013).

Las reacciones frente a este posible primer acercamiento fueron diversas, e incluyeron tanto voces en contra como opiniones a favor. En el primer grupo se ubicaron el entonces senador liberal y hoy funcionario del Gobierno, Rafael Pardo, y la excanciller colombiana María Emma Mejía, quienes advirtieron que entrar a la OTAN sería un error estratégico con Venezuela luego de que Colombia hubiera intentado adquirir tanques a España, y una idea peligrosa e indeseable para Colombia. En el segundo grupo estuvieron algunos sectores del Ejército colombiano, los cuales se mostraron entusiasmados con la iniciativa y consideraron que era el siguiente paso en la lucha contra lo que denominaron como un "comunismo disfrazado" ("Controversia por interés...", 2013).

La segunda etapa, que llamaremos de desarrollo sustancial, se produce entre 2012 y 2013, cuando el Gobierno colombiano pasa del discurso a la acción y consigue la elaboración y firma provisional de un primer acuerdo con la OTAN, el cual consiste en un Convenio de Cooperación e Intercambio de Información, siendo el primer memorando de esta naturaleza que la Organización suscribe con un país latinoamericano. A continuación, se resumen los detalles y características clave del acuerdo preliminar que alcanzó Colombia con la OTAN, de acuerdo con la información

7 Curiosamente el caso de la adhesión de Argentina como socio "extra-OTAN" no significó ni una crisis en el Mercosur, ni la ruptura de la Alianza Estratégica entre el país austral y Brasil. Si bien hubo algún malestar mientras se realizaron las negociaciones del estatus con Argentina en la Alianza, esto no impidió la firma de la Declaración de Río y de su Memorando de Entendimiento en 1997 (García \& Bruzzone, 2012). 
recogida en Croda (2013), Reyes y Saiz (2013), El Universal (2013) y "Las claves del acuerdo de Colombia..."(2013).

El acuerdo se suscribió en junio de 2013, en el cuartel general de la OTAN, localizado en Bruselas (Bélgica). Su objetivo general fue desarrollar un amplio marco de actividades de cooperación que contribuyeran al fortalecimiento de las capacidades de las Fuerzas Armadas, en tanto que sus objetivos específicos se pueden sintetizar de la siguiente manera:

- Estrechar las relaciones de cooperación y seguridad con la UE (Unión Europea) y la OTAN y desarrollar conjuntamente iniciativas que promuevan la estabilidad y la seguridad internacional.

- Aprender de la OTAN, y compartir con la Organización la experiencia colombiana en la lucha contra el narcotráfico, contra grupos terroristas y otros delitos que cometen las organizaciones del crimen organizado transnacional.

- Tomar conocimientos en materia de formación de los miembros de las Fuerzas Armadas y aprender los altos estándares de la OTAN en materias como emergencias civiles y operaciones humanitarias y de paz, así como en asuntos asociados a la integridad, la transparencia y en materia de mecanismos anticorrupción.

- Fortalecer la cooperación colombiana con organismos multilaterales y otros países, y elevar los estándares técnicos y profesionales de las Fuerzas Armadas al nivel de las democracias más avanzadas del mundo, al mismo tiempo que se continúa desarrollando capacidades cada vez más efectivas en la lucha contra el terrorismo y el crimen organizado.

- Tener acceso a experiencias, buenas prácticas en materia de misiones de paz, misiones humanitarias, derechos humanos, justicia militar, procesos de transformación y mejoramiento del sector de defensa y seguridad, además de ayudar en la lucha contra el narcotráfico.

El desarrollo de este acuerdo no le otorga a Colombia el estatus de socio, sino de cooperación para intereses comunes. Ahora bien, en cuanto a las características y alcances del documento, cabe mencionar las siguientes:

- Permite la creación de medidas de intercambio, protección de la información y cooperación en seguridad.

- Está basado en el aprendizaje de Colombia en derechos humanos, justicia militar y educación a las tropas.

- En ningún caso implica o posibilita la presencia de tropas extranjeras en territorio nacional y tampoco que Colombia se convierta en miembro de esta organización.

- Este acuerdo constituye un "precursor" de cualquier posible futura cooperación con Colombia que los aliados desarrollen a través de la OTAN. 
Ante este contexto, las reacciones regionales e internacionales no se hicieron esperar. Los gobiernos de Venezuela, Nicaragua y Bolivia interpretaron el acuerdo como un primer paso de Colombia para convertirse en miembro de ese organismo y como una amenaza para la estabilidad regional. Por su parte, Brasil y Ecuador manifestaron su inquietud en razón a que algunas potencias que conforman la OTAN se han manifestado contra la integración y los asuntos internos del continente. Además, consideraron que el acercamiento podría amenazar la soberanía amazónica de los países latinoamericanos. En el caso de Bolivia, el gobierno solicitó hacer una convocatoria urgente para llevar a cabo una reunión extraordinaria del Consejo de Seguridad de Unasur para analizar los riesgos que podría tener para la región esta iniciativa colombiana. En respuesta, la OTAN, por medio de su portavoz, dijo que el proceso no era ningún "escándalo" y explicó que las amenazas de seguridad a las que se enfrentan los Estados hoy en día son globales y que la Organización estaba trabajando desde hace muchos años con socios globales.

Finalmente, la tercera fase de los acercamientos, que será denominada como fase residual, comprende dos cuestiones: la conclusión del trámite interno legal del Tratado Colombia-OTAN y la reflexión y las impresiones que deja este acercamiento inconcluso. Frente a lo primero, fue noticia que en 2015 la Corte Constitucional colombiana, en ejercicio de sus funciones y mandato constitucional, y luego de examinar el acuerdo de cooperación, lo declaró inexequible tras hallar vacíos de forma y fondo en el proceso de aprobación legislativa, así como de analizar las implicaciones anticonstitucionales de la categoría "información clasificada” que podría incluir información personal y datos personales sensibles ("Corte declaró inexequible...", 2015).

El contexto en el cual ocurrió la fase sustancial, esto es, la visita del líder opositor venezolano Enrique Capriles a Colombia, además de la permanente confusión que giró en torno al acuerdo con la OTAN, del cual muchos se enteraron hasta la declaración de inexequibilidad, reveló no pocas inquietudes en la manera en que el Gobierno colombiano dirige la política exterior. La búsqueda de una relación más estrecha, no solo con la OTAN sino también por una plaza en la Organización para la Cooperación y el Desarrollo Económicos (OCDE), no ha dejado siempre un buen balance y requiere de una gestión más acertada en el campo de las relaciones con los socios latinoamericanos.

Una primera inquietud es la manera en que el Gobierno ha explicado (y entiende) su interés en vincularse con la OTAN. En alguna ocasión, y ante las dudas que han rodeado este proceso durante varios años, el presidente colombiano comunicó que el acuerdo de información y seguridad estaba pensado para "iniciar todo un proceso de acercamiento, de cooperación, con miras también a ingresar a esa organización” (“Gobierno quiere ser socio...”, 2013).

Ante las duras críticas manifestadas por varios países latinoamericanos, el entonces ministro de Defensa, Juan Carlos Pinzón, aclaró que si bien no estaba contemplada la membresía de Colombia en esta Organización, el acuerdo se firmó porque el país ha puesto en marcha "una estrategia de cooperación internacional que se despliega en los ámbitos bilateral y multilateral", la cual "se fundamenta en una aproximación del sector a diferentes regiones del mundo con criterios estratégicos de prevención, cooperación y modernización para el fortalecimiento de la seguridad y la defensa nacional" ("Las claves del acuerdo...", 2013).

Luego vino la corrección de la OTAN al recordar una cuestión básica y fundamental, que era la imposibilidad práctica de que Colombia perteneciera a la OTAN al no estar geográficamente 
localizada en el eje del Atlántico Norte, al mismo tiempo que aclaraba que el supuesto plan de ingresar a esa organización no era más que una iniciativa de cooperación, sin que ello significase que haya "planes inmediatos para establecer una asociación formal entre la Alianza y Colombia" (“OTAN descarta el ingreso...”, 2013).

Esta serie de sucesos dejaron mal al Gobierno, y dieron la impresión de una cierta improvisación, algo que es especialmente preocupante a la luz de los requerimientos de un genuino acuerdo para convertirse en un socio "extra-OTAN" (como es el caso de Israel, Corea del Sur, Jordania, Tailandia, o Egipto), que incluye, entre otras cosas, estar de acuerdo y acompańar intensamente a EE. UU. en "sus prioridades estratégicas y operaciones militares" (Ramírez, 2013).

Frente a esto, la analista política Socorro Ramírez (2013) se preguntaba si acaso el Gobierno comparte, de manera integral, la concepción, las demandas, condiciones e implicaciones de las intervenciones globales de la OTAN, y estaría dispuesto a asumir el costo político y económico de tomar distancia de su vecindario a favor de una Organización con intereses y prioridades más bien alejados de los del cono sur americano. Por lo tanto, a futuro, el Gobierno colombiano debe procurar alcanzar un equilibrio entre sus intereses, tanto en el ámbito regional como en el global, para no poner en riesgo su capital diplomático recuperado en el vecindario.

Si se concreta la superación definitiva del conflicto armado interno en virtud de los distintos acuerdos de paz, o al menos se logra reducir su intensidad, Colombia también podría aprovechar la coyuntura al reorientar sus esfuerzos y acercarse a procesos y actores fuera del ámbito regional que le sean más beneficiosos en un posible escenario de posconflicto, reafirmando eso sí en todo momento su autonomía y soberanía para adoptar las decisiones estratégicas que más le convengan, sin permitir que las críticas externas neutralicen sus decisiones de política exterior.

\section{Análisis de las ventajas para Colombia derivadas de su participación (actual y eventual) en misiones internacionales de naturaleza militar (o relacionadas con seguridad y defensa)}

Lo "militar" atañe a una dimensión fundamentalmente social y a un fenómeno esencialmente humano. Militar es un término que tiene su origen en el vocablo latino militâris, que hace referencia a lo perteneciente o relativo a la milicia o a la guerra, y como concepto se utiliza en contraposición a lo civil. La noción misma está vinculada sobre todo a un conjunto definido por miembros, instituciones y procedimientos, que forman parte activa de las llamadas Fuerzas Armadas, definidas como el brazo armado y defensivo de un país, organizado por el gobierno con unos fines y características específicas, y regulado por el ordenamiento jurídico imperante de un Estado (Echavarria, 2011; Ministerio de la Defensa Nacional de Guatemala, 2015).

De acuerdo con la OCDE, entre el personal que comprenden las Fuerzas Armadas se incluyen los miembros del ejército, la marina, la fuerza aérea y otros servicios militares, así como los reclutas inscritos para el entrenamiento militar u otros servicios por un periodo determinado y en función de las necesidades nacionales. Esencialmente, se excluye de las Fuerzas Armadas a las personas con empleo civil en establecimientos públicos que se ocupan de cuestiones de defensa; a 
inspectores de aduanas, de frontera u otros servicios civiles armados, y a miembros de las reservas militares que no están actualmente en servicio activo (Organisation for Economic Cooperation and Development [OECD], 2003).

En referencia a las Fuerzas Armadas de Colombia, cabe anotar los siguientes elementos relevantes, a propósito de su posible involucramiento en una Operación de Mantenimiento de Paz (OMP): i) su fundamento se inscribe en el Capítulo VII de la Constitución Política de 1991, el cual destaca que su finalidad es la defensa de la soberanía, la independencia, la integridad del territorio nacional y del orden constitucional; ii) se determinó que las Fuerzas Militares no son deliberantes, excepto sobre asuntos que se relacionen con el servicio y la moralidad del respectivo cuerpo y con arreglo a la ley; iii) de acuerdo con Fabio Cordeiro, conforme a la Constitución Política vigente, "no hay restricción al envío de tropas al exterior en misiones de paz" (Cordeiro, 2015, p. 106). Ahora bien, aunque la participación en la Multinational Force and Observers (MFO) y en la Operación Atalanta respaldan esta aseveración, "lo que se debe obtener, por parte del poder ejecutivo, es la aprobación por el Congreso Nacional para la consecución del envío” (Cordeiro, 2015, p. 106).

Teniendo como referencia este panorama general sobre la cuestión militar, de seguridad y defensa en el caso colombiano, y además atendiendo a las lecciones y características de las Misiones Internacionales en el seno de la OTAN, a continuación se establecen algunas de las posibles ventajas, con su respectivo análisis, que tendría para Colombia su participación eventual en Misiones Internacionales de naturaleza militar de acuerdo con cuatro criterios y con base en "Afganistán y otras misiones de paz" (2009), García y Bruzzone (2012), Giavendoni Pita (2004), Le Jeune (2010), Presidencia de la República de Colombia (2015) y Vignolles (2003).

\section{Continuidad de la proyección del poder militar como instrumento de la politica exterior colombiana:}

Una eventual participación en algunas Misiones Internacionales de la OTAN constituiría un elemento de apoyo a la estrategia diplomática de buscar alianzas y acercamientos internacionales para posicionar a Colombia como un líder en temas de la defensa y la seguridad, primero en el ámbito hemisférico, y posteriormente en el global.

Como revela la experiencia de Argentina, su admisión como socio "extra-OTAN" es reconocida como una cuestión que materializa y consolida el uso del instrumento militar como expresión de su política exterior, un hito que no hubiese ocurrido sin que el país austral hubiese desarrollado un proceso prolongado que data de sus labores de mediación en la Guerra del Chaco, su integración en la Misión de Observadores en el Líbano en 1958 o el envío de fuerza naval a la Bahía de Fonseca, en Honduras, en 1990.

De acuerdo con Pablo Vignoles, del Center for Hemispheric Defense Studies, la intervención de un Estado en coaliciones militares internacionales y en Misiones Internacionales se traduce en una proyección de fuerza en apoyo de los intereses y objetivos de la nación, satisfaciendo, por un lado, la necesidad de legitimación militar por medio de la imposición de mandatos de la ONU en resguardo de la paz, y, por el otro, contribuyendo a la paz y a la seguridad internacional como valor agregado. Esto va en línea directa con la posición oficial del Gobierno colombiano de contribuir a "la 
seguridad y estabilidad globales, apoyando los principios de la Carta de las Naciones Unidas y las resoluciones del Consejo de Seguridad por medio de su participación en las OMP" (Presidencia de la República de Colombia, 2015).

2. Posibilidad de cerrar brechas de capacidad operativa en el nivel de una alianza militar intergubernamental única en el mundo:

Como revelan los casos de Eslovenia y Bulgaria, un acercamiento más estrecho de tipo militar y logístico a la OTAN puede tener dos efectos deseables y positivos en las Fuerzas Armadas: primero, lleva a las autoridades estatales a repensar obligatoriamente la estructura de sus Fuerzas Armadas como producto de las exigencias de operar en el marco de la OTAN. Segundo, como consecuencia de lo primero y en la búsqueda de aproximarse a las necesidades y expectativas de la Organización, los gobiernos son más proclives a emprender programas importantes de modernización del brazo militar estatal, lo cual puede venir acompańado de medidas para aumentar la transparencia y el control civil del ejército, así como para actualizar equipos y lineamientos estratégicos, entre otras cosas (Le Jeune, 2010).

De acuerdo con Manuel Giavedoni, de la Academia de Estrategia y Escuela Superior de Gendarmería Nacional, "Argentina ha tenido buena fortuna en su participación en OMP, sus bajas humanas han sido reducidas y no ha cargado con consecuencias legales o políticas adversas" (Giavendoni, 2004, p. 7). Y no es para menos, de acuerdo con estudios periodísticos, el envío de cascos azules a la ONU les ha valido, tanto a Argentina como a Guatemala, la posibilidad de adaptarse a tácticas de desarme y reintegración puestas en marcha en otros países, y además ha "impulsado una mayor conciencia en sus soldados sobre la protección a los derechos humanos tras los conflictos internos que dejaron incuantificables muertos y desaparecidos" (Torre, 2015). Esto es especialmente positivo en dos países que, aunque han vivido conflictos y guerras civiles, ahora son reconocidos contribuyentes en Misiones Internacionales y sus fuerzas militares son entrenadas en conductas vitales en conflictos internacionales (Torre, 2015).

De acuerdo con el entonces ministro de Defensa colombiano, Juan Carlos Pinzón, un acuerdo entre la OTAN y Colombia le permitiría al país tener acceso a buenas prácticas y a los estándares profesionales de esa organización en áreas como integridad y transparencia, operaciones humanitarias y de paz, y fortalecimiento de las capacidades de las Fuerzas Militares, entre otras ("Las claves del acuerdo...", 2013).

3. Formación de capacidades desde el contacto con las experiencias militares más profesionales a nivel global:

Tomando como base la escuela americana de pensamiento conocida como pragmatismo, en claro rechazo de la epistemología dualista y la metafísica de la filosofía moderna, y a favor de un enfoque naturalista que considera el conocimiento como resultado de una adaptación activa del organismo humano a su entorno (Field, 2002), se reconoce la importancia de la formación de capacidades y saberes a partir del contacto con experiencias ajenas a la propia. 
Al respecto, aunque las Fuerzas Armadas de Colombia son reconocidas a nivel nacional y regional en múltiples ámbitos, resulta fundamental que entablen un diálogo propositivo con unas contrapartes que son reconocidas no solo en sus respectivas regiones, sino también a nivel global. Por ello, la participación de las Fuerzas Armadas en Misiones Internacionales es la oportunidad ideal para aprender a través de la experiencia, un método que ha tenido resultados destacables en el área organizacional y de negociación, tal y como lo revelan las experiencias de la consultora española Grup Sural en Marruecos (Vilaseca, 2008).

Frente a las Misiones Internacionales que estarían "disponibles" para Colombia en el marco de la OTAN, se destaca el hecho de que las Fuerzas Militares del país podrían, en caso hipotético, entablar el diálogo propositivo mencionado con los siguientes cuerpos armados de la Organización, reconocidos además en sus áreas de experticia y su gran avance tecnológico:

- Francia: conserva una de las fuerzas militares más capaces de Europa en virtud de su autonomía operativa y material, así como de su fuerza de disuasión nuclear completamente independiente. Las fuerzas francesas tienen experiencia y han logrado importantes resultados en Afganistán y Mali frente a amenazas asimétricas terroristas. Gracias a su equipamiento, las fuerzas del país galo también cuentan con grandes conocimientos y habilidades en asalto anfibio, asalto de superficie y en transporte táctico (Majumdar, 2015).

- Gran Bretańa: a pesar de que no cuenta con grandes posibilidades en poder aéreo y submarino, mantiene un ejército bien entrenado y equipado y sus fuerzas de operaciones especiales, como el Servicio Aéreo Especial, son legendarias y casi inigualables (Majumdar, 2015). El país contribuye con cerca de 323 millones de libras al presupuesto de la ONU para sus misiones de mantenimiento de la paz en el mundo, y participa activamente en cuestiones de transporte y logística en la misión en la República Centroafricana (Fariza, 2014), y por medio de instructores militares en Somalia y Sudán del Sur ("Bolkovac: abusos sexuales de los soldados de la ONU”, 2015).

- Alemania: el país germano no solo está experimentando una reactivación de su aparato militar frente a los retos del presente siglo, sino que también se destaca por mantener una base y experiencia industrial capaz de diseñar y construir tanques y submarinos con alta tecnología. Los mayores aportes alemanes a la paz se dan en el campo de la financiación (7,1\% del presupuesto total de la ONU) y en capacitación (su Centro de Misiones Internacionales de Paz dispone de aproximadamente 1.500 expertos en prevención civil de crisis, negociación, mediación y desarme) (Sefrin, 2009).

4. Aprendizaje que llevaría a elevar los conocimientos y experticia acumulada de las Fuerzas Armadas en Operaciones de Mantenimiento de Paz (OMP):

Como se ha podido apreciar, y en razón de su origen y naturaleza, la OTAN está compuesta mayoritariamente por Estados de Europa como miembros de pleno derecho. 
Este hecho tiene una consecuencia particular para los intereses de Colombia en las Misiones Internacionales, y es la posibilidad de acceder a conocimientos, habilidades y experiencias de una región que, como lo subrayaron en su momento líderes como el rey Felipe de Bélgica o el que fuera primer ministro checo, Vladimir Spidla, es sinónimo de un nuevo comienzo que ha contribuido con la instauración de la paz entre viejos adversarios locales, y en varias regiones del mundo ("Los jefes de Estado europeos...", 2014; Spidla, 2004).

Y no es para menos, en los últimos diez años Europa ha liderado más de veintidós misiones de paz, que van desde el Congo hasta los Balances y Afganistán, y la Política Europea de Seguridad y Defensa ha gestionado crisis con numerosas operaciones militares, las cuales han incluido cuerpos diplomáticos, jueces, policías, soldados y marinos (“Afganistán y otras misiones de paz", 2009). En parte, las discusiones y reflexiones sobre la extensión del campo de acción de la OTAN son producto de esta "cuota” europea decidida por la paz y la estabilidad global.

\section{Análisis de las ventajas para Colombia derivadas de su participación (actual y eventual) en misiones internacionales de naturaleza política (o relacionadas con la democracia)}

Lo político es, en el presente, un término que es objeto de usos y abusos, y por ello se requiere concretar una aproximación adecuada para los fines de la presente investigación. Al respecto, con el ánimo de conseguir tal concreción se acude a la teoría de los campos del sociólogo y filósofo francés Pierre Bourdieu, específicamente a una reinterpretación útil de su visión del llamado campo político, y en consecuencia de lo que denomina como "capital político", otorgado a una entidad político-administrativa abstracta que es el Estado moderno.

Capital político se entenderá aquí como el conjunto de recursos de poder con los que cuenta un Estado y que corresponde a la posición que tal Estado detenta en medio de la estructura de poder internacional. Dicho esto, se entenderá aquí las ventajas y desventajas políticas en términos del capital político obtenido o perdido por el Estado, derivado de su localización en el espacio o sistema político internacional. Esta última, resultante de sus decisiones en materia de política exterior, aclarando que una decisión o grupo de decisiones puede convenir y/o afectar el acumulado de capital político estatal.

Haciendo hincapié en las ventajas y desventajas, resulta especialmente útil realizar una revisión de las llamadas "variedades” del capital político de Bourdieu con conciencia en los fines de la presente investigación. Lo primero es que al ser un capital que está basado totalmente en el reconocimiento, y al tener un carácter preponderantemente simbólico, una acertada decisión de política exterior se traduciría en un aumento en la percepción positiva y de confiabilidad del Estado en el escenario internacional (Meichsner, 2007, p. 14). En contraste, unas acciones erróneas, abusivas o temerarias frente al orden establecido pueden dar paso a cuestionamientos, escándalos e incidentes que podrían finalmente reducir el capital político acumulado y poner al 
Estado en una situación desfavorable en el campo de la política exterior, íntimamente ligado a otros campos como el militar, el diplomático, e incluso el cultural (Meichsner, 2007, p. 14).

Sobre la utilidad del concepto de Bourdieu solo resta mencionar dos cosas antes de entrar en las ventajas. Lo primero es que, tal y como ocurre en la teoría, el capital político del Estado en este caso también puede ser convertido en otro tipo de capital en favor de los intereses del Estado, esto es, que una acción oportuna en apoyo a una Misión Internacional en algún país puede traducirse en capital político interno o cultural, el cual, si es usado adecuadamente, puede elevar la favorabilidad de un gobierno y mejorar el posicionamiento de un país en el extranjero.

El segundo elemento es que el capital político también está ligado orgánicamente al ente o al Estado, y puede ser tan efímero como un cambio de gobierno o un cambio de política. Si los gobiernos que asuman la dirección del Estado toman el camino de no continuar u oponerse sustancialmente a una anterior política exterior (que estaba en apoyo de una intervención u operación internacional que le estaba generando una cierta posición en el sistema, por ejemplo), enfrentan el posible escenario de perder tanto el capital político acumulado, como la posición privilegiada que tenía el Estado en el campo político exterior (Meichsner, 2007, p. 15).

Dicho esto, a continuación, se exponen y analizan algunas de las principales ventajas políticas que tendría para Colombia su participación eventual en Misiones Internacionales relacionadas con la OTAN, tomando como referencia a su vez las ventajas militares ya descritas en el apartado anterior. Ahora bien, cabe advertir que tanto estas como las siguientes ventajas deben ser leídas, en paralelo, con el conjunto de desventajas que será abordado en los apartes posteriores. Esta información se basa en Ardila (2014), García y Bruzzone (2012), Lahera (2005), Myers (2006) y Vignolles (2003).

1. La participación activa y decidida en misiones internacionales es una evidencia fáctica de la puesta en marcha de una politica exterior concreta con intereses definidos:

Los gobiernos, en todo lugar y en todo momento, se deben enfrentar al problema de llevar el qué hacer al cómo hacerlo en el ejercicio de sus políticas públicas con el fin de enfrentar críticas y polémicas sobre sus cursos de acción. Esto es especialmente sensible cuando se refiere a la política exterior, entendida como un reflejo de la situación interna y como un subproducto de la capacidad de un Estado para organizar voluntades y esfuerzos en el exterior a favor de sus propios intereses. Por ello, los gobiernos deben estar atentos a implementar ${ }^{8}$ este tipo de políticas y así garantizar que el discurso y el diseño se vean reflejados, e idealmente tengan un impacto en la realidad.

Si se entiende de manera amplia la política de defensa y seguridad nacional de Colombia como una política pública, se revela el hecho de que esta, con su objetivo de posicionar a Colombia como un líder en temas de la defensa y la seguridad, primero en el ámbito hemisférico, y posteriormente en el global, resulta utópica e imposible si no se tradu-

8 El experto en políticas públicas, Eugenio Lahera, define la implementación como el "conjunto deliberado y secuencial de actividades del gobierno orientadas al logro de los propósitos y objetivos de las políticas, articulados en declaraciones oficiales de política" (Lahera, 2005, p. 2). En otras palabras, es aquel proceso continuo y administrado, que consiste en transformar en resultados los objetivos asociados con una política pública. Para Lahera, América Latina vive un déficit, no de políticas públicas correctas, sino de capacidad para implementar políticas en general (Lahera, 2005). 
ce en decisiones y resultados. Por ello, una participación más activa en las Misiones Internacionales de Paz (que tienen un carácter primordialmente multilateral, no invasivo de la soberanía, y están basadas en fundamentos altruistas elaborados) constituye una oportunidad destacable para poner en práctica dicha política estratégica.

2. La colaboración de Colombia en misiones y operaciones internacionales constituye un instrumento de intercambio y aprendizaje en los campos diplomático, democrático, de seguridad y defensa:

Tomando como referencia la teoría del aprendizaje basado en la observación y el fenómeno del modelamiento ${ }^{9}$, es posible sostener que el contacto de las autoridades nacionales con las instancias políticas de la Alianza Atlántica constituye un fenómeno dual compuesto por las siguientes cuestiones: por un lado, este acercamiento fue, y sin duda seguirá siendo, un desafío en virtud de la discontinuidad de la relación entre Colombia y la OTAN como consecuencia de las interrupciones y polémicas que ha despertado, a lo largo de los ańos, este tipo de contactos. La declaración de inexequibilidad de la Ley 1734 de $2014^{10}$, sumado a las falencias registradas en los esfuerzos del Gobierno central para explicar y justificar el acuerdo, son solo algunos reflejos de estos desafíos.

Asimismo, este contacto también traería importantes lecciones en materia de gestión de asuntos y problemas internacionales. De hecho, conocimientos y aprendizajes en cuestiones tan complejas como la seguridad de eventos públicos, la formación de capacidades estatales locales, la atención de emergencia ante desastres naturales en contextos de desarrollo (huracán Katrina en los EE. UU.) y subdesarrollo (terremoto en Pakistán), así como el fortalecimiento de las instituciones democráticas en periodos de posconflicto, no solo son experiencias valiosas para las Fuerzas Armadas, sino que también pueden proveer de lecciones que aporten en la formación del recurso humano del Estado colombiano, lo cual puede ser enormemente útil para enfrentar los desafíos $\mathrm{y}$ necesidades presentes y futuros dentro del territorio nacional.

3. La cooperación del Estado colombiano en iniciativas de otros Estados y bloques podría reforzar su posición relativa, e incluso le permitiría inaugurar nuevos vínculos con nuevos socios:

La política exterior de Colombia, desde un punto de vista teórico-conceptual, se ubica en el comportamiento esperado de las llamadas potencias regionales secundarias de América Latina. Al respecto, Martha Ardila, de la Universidad Externado de Colombia, señala que este conjunto de países (entre los cuales se incluyen, además de Colombia, a Venezuela, Chile y Argentina) "se valen del poder suave y de la diplomacia pública para mejorar su imagen, ejercer liderazgo, construir nuevas alianzas y buscar un nuevo equilibrio de poder regional" (Ardila, 2014, p. 90). Esta cuestión pone en evidencia dos

9 De acuerdo con el profesor de psicología David Guy Myers, el aprendizaje se logra no solo mediante el condicionamiento, sino también sobre la base de la observación de los demás. El aprendizaje basado en la observación, que consiste en observar e imitar a los otros, se funda en un proceso denominado "modelamiento", por medio del cual se visualiza e imita una conducta específica (Myers, 2006, p. 336). Ahora bien, este tipo de aprendizaje solo constituye una parte en la compleja tarea de asimilación y adaptación de habilidades y conocimientos ajenos.

$10 \mathrm{Si}$ el lector desea consultar el documento original del Acuerdo, puede acudir al siguiente link web: https://www.mindefensa.gov.co/irj/go/km/docs/Mindefensa/Documentos/descargas/Agenda\%20Legislativa/Proy_ley_acuerdo_OTAN.pdf 
grandes consecuencias de singular valor para la reflexión sobre las ventajas de una hipotética inserción de Colombia en Misiones Internacionales auspiciadas por la OTAN.

En primer lugar, la participación en Misiones Internacionales a favor de la paz no es un ejercicio ajeno a la política exterior de una potencia regional secundaria. De hecho, la experiencia chilena demuestra que la participación activa en este tipo de iniciativas, en lugares tan disímiles y lejanos al ámbito de influencia inmediata chilena como Camboya, Bosnia-Herzegovina y Chipre (que significó un hito al registrarse por primera vez un trabajo conjunto, bajo un mismo mando, de fuerzas chilenas y argentinas) forma parte del ejercicio del poder blando, pues corresponde a la promoción de determinados temas de interés (tales como resolución pacífica de controversias, democracia, seguridad humana) en espacios de cooperación horizontal y multilateral con países con similares intereses (Fuentes, 2006, pp. 2-6). Esto permite sostener que la participación de Colombia en Misiones Internacionales no solo no es extraña a su estrategia de inserción internacional, sino que también es deseable si pretende elevar su influencia y aproximarse a nuevos aliados.

En segundo lugar, la experiencia de Argentina como aliado "extra-OTAN", fenómeno sobre el cual ya se había hecho mención, reveló algunos elementos a favor del posicionamiento del país austral tanto en el ámbito latinoamericano, como en el internacional, entre los cuales se destacan: i) acentuadas manifestaciones públicas de agradecimiento al gobierno argentino, principalmente de EE. UU. y de otros Estados, por su contribución a la paz y a la seguridad mundial, en las cuales se reafirma el carácter democrático del régimen argentino; ii) prioridad para acceder a material y recursos excedentes de defensa bajo un régimen financiero especial ${ }^{11}$; iii) acceso preferencial a programas de cooperación de entrenamiento; $i v$ ) ser tenido en cuenta en acuerdos de investigación y desarrollo con el Departamento de Defensa de los EE. UU., y $v$ ) ser elegible para que empresas del sector privado argentino participen en licitaciones y contratos de mantenimiento, reparación o reacondicionamiento de equipos americanos (Vignolles, 2003, p. 160).

\section{Análisis de las desventajas para Colombia derivadas de su eventual participación en misiones internacionales de naturaleza militar (o relacionadas con seguridad y defensa)}

Un análisis de los impactos, de naturaleza militar, que tendría una hipotética participación de Colombia en Misiones Internacionales relacionadas con la OTAN estaría en gran medida incompleto si solo se observaran las ventajas. $\mathrm{Al}$ respecto, a pesar de que los elementos positivos pueden ser numerosos, es importante también detenerse y analizar algunas de las principales desventajas

11 Específicamente, Argentina aprovechó su estatus “extra-OTAN” para adquirir múltiples equipos militares, entre los cuales se incluyeron: 25 aviones Mohawk de vigilancia y reconocimiento para el Ejército, una versión mejorada del avión de ataque A4M para la Fuerza Aérea, y varios helicópteros y buques auxiliares para la Armada (Ay, 2007; Vignolles, 2003, p. 160). 
que tendría para el país una participación de sus Fuerzas Militares en este tipo de misiones, con el fin de obtener un panorama suficientemente integral que permita extraer conclusiones valiosas que guíen, si es el caso, uno o varios cursos de acción y decisión presentes o futuros.

Dicho esto, a continuación, se presentan estas desventajas, con su respectiva reflexión, de manera amplia, fundamentadas además en pasadas experiencias derivadas de casos con características similares a lo que sería eventualmente el caso colombiano. Este análisis se basa en Arteaga (2015), Benítez (2007), César (2001), "Bolkovac: abusos sexuales de los soldados de la ONU” (2016), Forte (2007), Fuentes (2006), Giavendoni Pita (2004), ONU (2015) y Rodríguez (2016).

\section{Costos materiales y humanos como caracteristica connatural de la participación en misiones} internacionales relacionadas con la Alianza Atlántica:

Los llamados presupuestos bianuales de financiación común de la OTAN recuerdan una máxima que rige el sistema internacional, que es que no hay acción o impacto sin costo, aun cuando esta acción se funde en algún principio altruista. De acuerdo con Marcelo Péndola, jefe de I \& D del Centro Conjunto para Operaciones de Paz de Chile (Cecopac), "la decisión de Participar en una determinada operación de paz, necesariamente deberá hacerse previo análisis de los costos y riesgos involucrados" (Péndola, 2005, p. 450), y en el caso chileno esta tarea pasa por la Política Nacional para la Participación del Estado de Chile en Operaciones de Paz, que estipula que un grupo de análisis especializado deberá evaluar cada petición, ponderar los costos versus los beneficios, y elaborar una proposición al presidente de la República (Péndola, 2005, pp. 450-451).

Dicho esto, el país no solo debe elaborar un marco regulatorio diseñado para reflexionar sobre la participación en Operaciones de Paz, sino que también debe estar dispuesto a asumir costos absolutamente variables para sus Fuerzas Armadas, entre los cuales se debe incluir necesariamente pérdidas humanas y pérdidas materiales. La cuestión no es de poca importancia si se tiene en cuenta no solo que el país aún atraviesa un costoso conflicto armado interno, sino también que las OMP le han costado a organizaciones como la ONU (y a sus aportantes) más de tres mil muertos en actos oficiales al servicio de la paz y la seguridad internacional (ONU, 2015).

España, por ejemplo, ha perdido más de cien soldados desde sus participaciones en OMP en 1987; solo la misión de la Fuerza de Protección de las Naciones Unidas (Unprofor, por su sigla en inglés) en la ex-Yugoslavia costó a sus participantes (incluida Argentina) más de cuatro mil millones de dólares (Benítez, 2007, p. 106). Y, a pesar de no vivir un conflicto interno, las naciones aportantes deben convivir con trágicas noticias de soldados suyos muertos por hechos en el exterior, como ocurrió en BosniaHerzegovina cuando una mina terrestre se detonó al paso de un vehículo del Batallón argentino y dejó seis víctimas mortales (Giavendoni, 2004, p. 3). Esta cuestión debe ser objeto de un debate nacional profundo, más aún cuando el país registra, por ejemplo, más de diez mil víctimas de minas antipersonales y municiones sin activar desde 1990, de las cuales 6.222 son militares y 3.779 son civiles ("Minas antipersonales...", 2012). 
2. Riesgo de exposición innecesaria de las Fuerzas Militares y del Estado a polémicas ante posibles violaciones de normativas locales e internacionales:

Gracias a la irrupción de los llamados medios de comunicación masivos o MCM, la difusión de información en tiempo real se ha globalizado como nunca antes. Este hecho ha tenido efectos diversos, entre los cuales se destaca la influencia mediática que termina inevitablemente permeando la interacción entre la sociedad civil y las Fuerzas Armadas (César, 2001, pp. 150-151). De acuerdo con Mariano César, de la Universidad de Buenos Aires (UBA), "la cobertura periodística de un despliegue militar estará fuertemente influenciada por la forma en que los MCM cuentan la historia [...]. La experiencia indica que el periodismo puede contar la historia de una operación militar de manera lesiva a la imagen de las Fuerzas Armadas involucradas" (César, 2001, p. 158).

En el marco de las operaciones de paz, sean estas auspiciadas por la ONU o por la OTAN, es especialmente preocupante el efecto usualmente descontextualizador de los MCM, pues se nota una tendencia a privilegiar los momentos críticos de mayor tensión, soslayando etapas de precrisis que, a pesar de su gravedad, tienen un contenido y una dinámica que no genera gran interés en las audiencias (César, 2001, pp. 159-160). Dado que los equipos de noticias enviados no cuentan, en la mayoría de los casos, con la experiencia necesaria para comprender el contexto de las Misiones Internacionales en su totalidad, es muy probable que se produzcan entendimientos parciales e incompletos de los hechos. Por supuesto esto no significa que no haya sucesos que ameriten un rechazo y la identificación de responsabilidades.

El problema de exposición que podrían enfrentar las Fuerzas Armadas no es de poco valor si, además del fenómeno lesivo de influencia mediática, se subrayan los múltiples escándalos por violaciones de derechos humanos cometidos por integrantes de las Misiones Internacionales de Paz de la ONU y de la OTAN, conocidos desde 1997 y amplificados por los MCM desde el 2000. De acuerdo con la socióloga Daniela Forte, con la salida a la luz pública de los abusos en Kosovo, lo que parecía ser un caso aislado en Somalia surgía como un patrón común de explotación dentro de las misiones de la ONU, algo que quizá no sea simplemente una presunción en razón a las serias acusaciones al Organismo de cerrar las investigaciones y desacreditar a los testigos ("Bolkovac: abusos sexuales de los soldados de la ONU", 2016; Forte, 2007, pp. 131-132). Sea cual sea la verdad, lo que sí es seguro es que el argumento de que los comportamientos individuales no pueden ser controlados ya no es válido, y aquellos que quedan más damnificados en su imagen son los Estados, sin mencionar las implicaciones en el terreno judicial. En el caso mencionado, se publicará el país de origen de los soldados culpables de estos abusos, y estos países quedarán fuera de las misiones de paz (Rodríguez, 2016).

3. Posibilidad de extra-dimensionar ciertos tipos de participación militar, y opacar otro tipo de aportes de Colombia que también podrían ser valiosos en misiones internacionales:

Si vis pacem, para bellum es una máxima latina que, en virtud del uso y el abuso en la cultura popular, ha tenido un efecto de sobredimensión del factor militar, específica- 
mente del uso de la fuerza armada. Este fenómeno ha favorecido el uso exclusivo de la fuerza para resolver un amplio abanico de problemáticas multifacéticas, lo cual no solo ha generado impactos alejados de los objetivos esperados, sino también ha producido una serie de efectos colaterales negativos que en ocasiones son difíciles de calcular.

Entre los numerosos ejemplos es posible citar las conclusiones del estudio titulado " ¿Las intervenciones militares en la Guerra contra el narcotráfico en México aumentaron la violencia?", adelantado en 2015 por Daniela Espinosa y Donald Rubin. El informe final demostró que durante el primer año de las intervenciones militares se registró un aumento promedio de casi once homicidios por cada cien mil habitantes en las dieciocho regiones mexicanas analizadas. Aunque se presume que este aumento en la violencia puede ser fruto de la fractura de las estructuras de poder en las zonas (Arteaga, 2015), también queda en evidencia que el plan de militarización no podría soportar un periodo más largo en operación sin incluir otro tipo de programas que comprendan la promoción de alternativas de formación y empleo para los jóvenes de los estratos bajos, el diálogo entre líderes comunitarios, la mejora en las relaciones y el entendimiento entre el Estado y los residentes locales, entre otros.

La experiencia descrita, aplicada en términos amplios y flexibles a las Misiones Internacionales a las que el Estado colombiano, por medio de sus Fuerzas Militares, aspira a participar de manera más decidida, debe dar lugar a una reflexión no sobre los fines (posicionar a Colombia como un líder en temas de la defensa y seguridad), sino sobre los medios para alcanzar dichos fines. Aunque la tendencia que genera mayor visibilidad es el envío de contingentes militares armados y capacitados para enfrentar desafíos de seguridad, el Estado también puede optar por caminos alternos que generan impactos importantes sin ignorar los objetivos de su Diplomacia en Seguridad y Defensa. Por ejemplo, puede contribuir con instructores y técnicos militares para fortalecer las capacidades locales de vigilancia e inteligencia, puede enviar especialistas militares y civiles en cuestiones de acción integral y mejora de las relaciones cívico-militares, e incluso podría colaborar poniendo a disposición su experticia en desminado, erradicación de cultivos ilícitos, y logística y transporte en zonas geográficas adversas, entre otras.

\section{Análisis de las desventajas para Colombia derivadas de su eventual participación en misiones internacionales de naturaleza política (o relacionadas con la democracia)}

Como ya se había explicado en detalle, la dimensión de lo político, y por añadidura lo entendido aquí como ventajas o desventajas, toma varios puntos, a modo de reinterpretación útil, de la teoría de los campos de Bourdieu. La cuestión de las desventajas será entonces entendida aquí en términos de capital político perdido por el Estado como resultado de ciertas decisiones y acciones en materia de política exterior, que además le acarrean un lugar desfavorable en el sistema polí- 
tico internacional, así como una percepción menos positiva en otros campos, tanto en el ámbito doméstico como en el exterior.

En virtud de que la presente reflexión se funda, sobre todo, en análisis sobre eventuales escenarios que podría enfrentar Colombia en las Misiones Internacionales, se considerará una serie de posibles inconvenientes que le acarrearían al Estado una pérdida sustancial de su capital político y una deslocalización desafortunada en el escenario internacional. Un hecho que sería visto como un producto contrario a los lineamientos de la llamada Diplomacia Colombiana de Seguridad y Defensa. Dicho esto, a continuación se exponen algunas de las principales desventajas para Colombia derivadas de su eventual participación en Misiones Internacionales de naturaleza política (o relacionadas con la democracia). La información se basa en Baracaldo (2013), "Minas antipersonales dejan..." (2013), "Son cinco los muertos", (2016), García y Bruzzone (2012), "La monarquía está enfurecida...” (2016) y Vignolles (2003).

1. Costos politicos y diplomáticos derivados de involucrarse con una alianza de seguridad extraña a América Latina y en territorios incluso hostiles:

Como ocurrió en su momento con Argentina, principalmente, y con Chile, de manera secundaria ${ }^{12}$, el Gobierno colombiano ya ha tenido que enfrentar algunos costos políticos y diplomáticos en su vecindario inmediato derivados no de su intención de participar en Misiones Internacionales, pero sí por su acercamiento a la OTAN. Como se mencionó anteriormente, las reacciones de los países vecinos de América Latina fueron de rechazo y contribuyeron a gestar un ambiente de desconfianza hacia el Estado colombiano (“Controversia por interés...", 2013). Y no es para menos, dado el malestar que generó el conocimiento de un acercamiento tan "maduro" justo luego de haberse celebrado distintas reuniones y eventos relacionados con la integración latinoamericana, como fue el caso de la primera cumbre de la Comunidad de Estados Latinoamericanos y Caribeños (Celac) en Santiago de Chile a principios de 2013.

En el caso argentino, por ejemplo, la negociación y el nombramiento del país austral como aliado "extra-OTAN" generó un cierto grado de malestar en Chile y Brasil, que si bien no implicó una crisis en el Mercosur, ni la ruptura de la alianza estratégica entre Argentina y Brasil, sí le dio varios dolores de cabeza al gobierno austral, al cual se le acusó de no consultar con sus socios latinoamericanos su acercamiento a la OTAN. Al respecto, se pudo apreciar que en 1999 la cuestión de las Misiones Internacionales y la OTAN le había restado maniobrabilidad a Argentina en su propia región, por lo cual tuvo que abandonar la idea de incorporarse como miembro asociado (bajo una nueva categoría) a la OTAN. Incluso algunos analistas consideran que el acercamiento a la

12 Curiosamente, Chile ha tenido que sortear algunas problemáticas derivadas de su participación en Misiones Internacionales a pesar de sus alcances limitados para la seguridad regional, sus escasas contradicciones con intereses de los países vecinos, y sus fundamentos humanitarios. Al respecto se destaca el caso de su participación en Haití, en la cual se registró un desacuerdo sustancial entre el Congreso y el presidente de la República a raíz de la autorización de salida de contingentes. De acuerdo con Péndola: "En esa oportunidad se corrió el riesgo de politizar el tema de la participación en operaciones de paz, situación que habría dificultado en gran medida el cumplimiento por parte de nuestro país de este compromiso nacional” (Péndola, 2005, p. 451). 
Organización no derivó en reales beneficios ni en una mejor posición política internacional para Argentina (García \& Bruzzone, 2012; Vignolles, 2003, pp. 161-162).

Asimismo, el Estado colombiano también debe sopesar las posibles implicaciones que tendría intervenir activamente en escenarios sensibles para la política doméstica de países tan lejanos y distintos, sobre los cuales se tiene algún grado de relación o casi ningún conocimiento en absoluto. Como bien reseña Péndola (2005), a pesar de que la mayoría de Misiones Internacionales se traten de actividades legitimadas por organismos como la ONU, y a pesar de que en ocasiones (incluso con la OTAN) se debe buscar cierta aprobación de parte de las autoridades del Estado receptor de las operaciones de paz, intentando así evitar situaciones que podrían despertar el rechazo a la acción de las fuerzas en el área de conflicto, aún pueden presentarse contraposiciones con los intereses nacionales de otros países, lo cual afectaría las relaciones bilaterales, tanto presentes, como futuras (Péndola, 2005, p. 451).

Este es un campo sensible en el que Colombia no tiene una experiencia sustancial, algo que es especialmente preocupante si se tiene en cuenta la gran susceptibilidad del campo diplomático mundial. Un ejemplo que recuerda esta última cuestión se encuentra en los recientes sucesos que rodearon la conferencia internacional sobre el Sahara Occidental celebrada en el Senado de Colombia, y que contó con la participación de altos representantes del pueblo saharaui. El evento suscitó una gran molestia de parte del Reino de Marruecos, que lo consideró como una bofetada a las buenas relaciones bilaterales, a pesar de que fue un acto de la rama legislativa y no del Gobierno colombiano ("La monarquía está enfurecida...", 2016).

2. Dada la coyuntura del proceso de paz doméstico se podría percibir como una contradicción el apoyo de Colombia a misiones militaristas internacionales en zonas de conflicto:

En un país que ha vivido durante más de cincuenta años un cruento conflicto armado interno y que hoy vislumbra una oportunidad histórica para resolverlo por medios políticos, el escenario hipotético de participar activamente en misiones con alto contenido militar, en zonas de conflicto, genera no pocos interrogantes y debates sobre su misma idoneidad política presente y futura.

El primer interrogante es la percepción interna frente a un posible involucramiento en el extranjero con componentes militares. Al respecto, el Gobierno debe ser consciente de que cuando se presente realmente la oportunidad, deberá hacer frente a una opinión pública que ha estado atravesada por la experiencia histórica del conflicto y la confrontación armada. Los apoyos de la sociedad a este tipo de iniciativas no son certeros, y quizá se deberán asumir tareas de pedagogía y de concientización sobre la relación entre las Misiones Internacionales y los compromisos del Estado frente a la paz y la seguridad internacional. Ahora bien, si se tiene en cuenta la experiencia chilena reciente, en la cual se evidencia que la opinión pública se muestra confundida y crítica frente a la posibilidad de enviar misiones de paz a África, se reconoce que esta pedagogía puede resultar insuficiente $y$, por tanto, no se traduciría en un apoyo automático y masivo (Péndola, 2005, pp. 451-452). 
El segundo interrogante está relacionado con la genuina capacidad del Gobierno para justificar gastos y penurias para las Fuerzas Armadas, y en últimas para el Estado, en regiones y países lejanos y extrańos para la sociedad colombiana. Citando nuevamente el caso chileno frente a los esfuerzos de paz en África, se aprecia cómo puede resultar desafiante justificar un gasto humano y material en zonas de conflicto que poco o nada se asocian con los intereses y las problemáticas internas más urgentes, más aún cuando el país todavía tiene profundos deberes pendientes en seguridad — hecho que los recientes incidentes armados solo reafirman- (Baracaldo, 2013; "Son cinco los muertos...", 2016).

En tercer lugar, es poco probable que acudir a un hipotético otorgamiento de una categoría de aliado "extra-OTAN" contribuya a mejorar la percepción crítica frente a un acercamiento a la OTAN, e incluso estaría en contravía de la visión de un país en paz en los próximos años. Como se ha podido notar a lo largo del documento, la experiencia argentina como aliado "extra-OTAN" no produce un consenso definitivo sobre los beneficios para el capital político o para el posicionamiento argentino en el escenario local o internacional. De hecho, los analistas aún debaten sobre la conveniencia real de este tipo de acercamientos, especialmente para países que no están en la órbita geopolítica original de la Organización (Vignolles, 2003, pp. 161-162).

Un posible otorgamiento para Colombia de este estatus especial no necesariamente estaría en concordancia ni contribuiría a la visión de una Colombia en paz en los próximos ańos, tal y como está planteado por el Gobierno actual. Nuevamente, en referencia a la experiencia argentina, si algo pudo ser magnificado fueron los importantes aportes materiales (de tipo bélico) que obtuvo el país austral de su estatus especial. Para un país cuyos diálogos y debates contemplan, como elemento del denominado posconflicto y como contribución a la construcción de paz, una reorientación necesaria de las tareas de las Fuerzas Militares hacia actividades ajenas de la guerra irregular, tales como ayuda y alivio ante emergencias naturales, erradicación de cultivos ilícitos, desminado humanitario y reconstrucción de infraestructura, no es muy claro de qué forma un estatus como el de socio "extra-OTAN" podría contribuir efectivamente. De hecho, el recibir armamento pesado, como ocurrió con Argentina, estaría en contravía de la misma transformación de las Fuerzas, y sería en última instancia un elemento que obstaculizaría un proceso interno de hipotética reorientación militar.

Quizás el Gobierno nacional pueda explorar caminos para que su acercamiento a la OTAN, a largo plazo, se traduzca en recursos genuinos de construcción de paz. Este puede ser el caso de ciertas Misiones Internacionales que por sus características constituirían oportunidades excepcionales para conocer y construir capacidades y experiencias valiosas en materia de posconflicto y seguridad, las cuales además podrían ser aplicadas en un futuro cercano. 


\section{Conclusiones}

El presente documento tenía como objetivo reflexionar sobre el posible impacto político y militar de la participación de las Fuerzas Militares de Colombia en Misiones Internacionales relacionadas con la OTAN. Para lograr dicho objetivo se abordaron diversas cuestiones, incluyendo un análisis del funcionamiento, los logros y los desafíos de la Organización en estas misiones, de las relaciones históricas y vigentes con Colombia, y finalmente del conjunto de ventajas y desventajas en naturaleza militar y política asociadas a la participación actual y eventual del país en dichas operaciones internacionales.

A pesar de la amplitud de la temática y de las múltiples implicaciones que tendría este involucramiento en el corto, medio y largo plazo, la presente reflexión permite aproximarse a tres conclusiones puntuales. La primera consiste en que la OTAN es y seguirá siendo la única organización con capacidad global, capaz de realizar misiones y operaciones de distinta índole en las más diversas condiciones. Este rasgo particular la ha llevado a fijar como prioridad el trato con terceros Estados, un hecho que debe ser visto de manera estratégica por aquellos gobiernos interesados en asociar a sus Estados de manera más estrecha con la Organización y beneficiarse así de una experticia invaluable en áreas como la vigilancia, la defensa preventiva y la creación de capacidades locales.

La segunda conclusión es que los acercamientos del Estado colombiano a la Alianza Atlántica no han sido siempre llevados a cabo de manera estratégica y acertada, a pesar de que estas "relaciones" datan de 2010. Al respecto, se logró identificar una suerte de línea de tiempo de tres etapas: una exploratoria, que inicia en 2006 y en la cual se contempló la posibilidad de que Colombia se convirtiera en socia de la OTAN bajo la categoría "miembro extra" o aliado "extra-OTAN", en el marco de un plan por conseguir un grupo de países latinoamericanos "amigos” de la Organización. La siguiente etapa, entre 2012 y 2013, fue de desarrollo sustancial y su producto fue la elaboración y firma provisional de un primer acuerdo con la OTAN, el cual consiste en un Convenio de Cooperación e Intercambio de Información. Cabe agregar que se trató del primer memorando de esta naturaleza que la Organización suscribió con un país latinoamericano. Finalmente, la tercera etapa, denominada fase residual, comprendió dos cuestiones: la finalización del trámite interno legal del Tratado Colombia-OTAN y la reflexión y las impresiones que deja este acercamiento aún no terminado.

La tercera y última conclusión se relaciona con el balance que deja el análisis del conjunto de ventajas y desventajas, en materia militar y política, que tendría para Colombia una participación en Misiones Internacionales relacionadas con la OTAN. Como ocurre con la gran mayoría de las decisiones en materia de política pública, los efectos pueden contener tanto elementos positivos como negativos; potenciar los primeros frente a los segundos depende en buena medida del diseño normativo de los compromisos (producto de una negociación), así como de las capacidades de gestionar su implementación.

Para Colombia, quizá la lección principal que deja este ejercicio radica en la necesidad de explorar caminos para que su acercamiento a la OTAN, a largo plazo, se traduzca en recursos genuinos de construcción de paz, como es el caso de ciertas Misiones Internacionales que no solo pueden constituir oportunidades excepcionales para desarrollar capacidades y experiencias valio- 
sas en materia de posconflicto y seguridad, sino que además pueden ser aplicadas en un futuro cercano. Sin embargo, es importante que Colombia reafirme en todo momento su autonomía y soberanía para que adopte las decisiones estratégicas que más le convengan, sin permitir que las críticas externas neutralicen sus decisiones de política exterior.

\section{Referencias}

1. Afganistán y otras misiones de paz [Editorial]. (2009). Estudios de Politica Exterior, 132. Recuperado de http:// www.politicaexterior.com/articulos/politica-exterior/editorial-afganistan-y-otras-misiones-de-paz/

2. Aliboni, R. (2011). El nuevo Concepto Estratégico de la OTAN y el Mediterráneo [documento en línea]. Recuperado de http:// www.iemed.org/observatori-es/arees-danalisi/arxius-adjunts/ anuari/med.2011/Aliboni_es.pdf

3. Alto Comisionado de las Naciones Unidas para los Refugiados [ACNUR]. (2011). Cooperación internacional para compartir las cargas y las responsabilidades. Reunión de expertos en Amman, Jordania, 27 y 28 de junio de 2011 [documento en línea]. Recuerado de http://www.acnur.es/ PDF/8272_20120112114430.pdf

4. Alto Comisionado de las Naciones Unidas para los Refugiados [ACNUR]. (4 de marzo de 2016). ACNUR propone directrices para resolver la crisis de los refugiados en Europa [noticia en página web]. Recuperado de http:// www.un.org/spanish/News/story.asp?newsID=34586\#. Vtx0leasnUI

5. Ardila, M. (2014). Características de inserción internacional de potencias regionales latinoamericanas. A propósito de Colombia y Venezuela. OASIS, 19, 87-101.

6. Arteaga, A. (6 de abril del 2015). Intervención militar generó más violencia, sugiere estudio. Milenio. Recuperado de http://www. milenio.com/policia/Intervencion_militar_violencia_estudio-violencia_narco_Ejercito-Valeria_Espinosa_0_494950699.html

7. Arteaga, F. (2010). El nuevo Concepto Estratégico de la OTAN: lógica y estructura. Análisis del Real Instituto Elcano (ARI), 72, 1-9.

8. Ay, C. (2007). Grumman OV-1D Mohawk. Recuperado de http://aeromilitaria.com.ar/ea/fleet/mohawk/index.htm

9. Baracaldo, D. (22 de julio de 2013). ¿Cuáles son las zonas 'rojas' por violencia en Colombia? KienyKe. Recuperado de http://www.kienyke.com/politica/las-zonas-de-mas-violencia-en-colombia/

10. Barf, B. (2014). Los verdaderos problemas de Libia. Revista de la OTAN. Recuperado de http://www.nato.int/docu/ review/2014/Also-in-2014/Security-political-problemsLibya/ES/index.htm
11. Benítez, R. (2007). América Latina: operaciones de paz y acciones militares internacionales de las fuerzas armadas. Foro Internacional, 47 (1), 99-116.

12. Blasco, F. (2014). Las dificultades de la OTAN actual a la hora de tomar decisiones [artículo en línea]. Kosmos-Polis. Recuperado de http://www.uma.es/foroparalapazenelmediterraneo/?p=1931

13. Cattori, S. (23 de marzo de 2013). Interview with Mahdi Darius Nazemroaya: "NATO only yields destructions, insecurity and misery. It must be abolished" [artículo en línea]. Recuperado de http://www.silviacattori.net/spip. php?article4325

14. Cembrero, I. (7 de noviembre de 1991). La cumbre de la OTAN analiza en Roma el vacío estratégico en el Este de Europa. El Pais. Recuperado http://elpais.com/diario/1991/11/07/internacional/689468408_850215.html

15. César, M. (2001). Influencia de los Medios de Comunicación en la relación Opinión Pública-Fuerzas Armadas. Revista Política y Estrategia (85), 150-170.

16. Colombia firma acuerdo de cooperación estratégica con la OTAN. (25 de junio de 2013). El Universal. Recuperado de http://www.eluniversal.com/internacional/130625/colombia-firma-acuerdo-de-cooperacion-estrategica-con-la-otan

17. Conde, J. (2000). La Alianza Atlántica y el nuevo concepto estratégico. Afers Internacionals, 49, 19-25.

18. Controversia por interés de Colombia en la OTAN. (3 de junio de 2013). El Espectador. Recuperado de http://www. elespectador.com/noticias/temadeldia/controversia-interes-de-colombia-otan-articulo- 425758

19. Cordeiro, F. (2015). Operaciones de mantenimiento de paz de la ONU y la proyección de las Fuerzas Militares de Colombia (Monografía de maestría). Escuela Superior de Guerra, Bogotá D. C.

20. Corte declaró inexequible acuerdo de cooperación entre Colombia y la OTAN. (3 de junio de 2015). El Espectador. Recuperado de http://www.elespectador.com/noticias/ judicial/corte-declaro-inexequible-acuerdo-de-cooperacion-entre-articulo-564333

21. Croda, R. (12 de julio de 2013). Colombia-OTAN: Un acuerdo incómodo. Proceso. Recuperado el 2016, de http:// 
www.proceso.com.mx/347282/colombia-otan-un-acuerdo-incomodo

22. Bolkovac: abusos sexuales de los soldados de la ONU. (2 de marzo de 2016). Deutsche Welle. Recuperado de http:// www.dw.com/es/bolkovac-abusos-sexuales-de-los-soldados-de-la-onu/a-19087962

23. Dobbins, J. (2005). El papel de la OTAN en los procesos de reconstrucción nacional [artículo en línea]. Revista de la OTAN. Recuperado de http://www.nato.int/docu/review/2005/issue2/spanish/art1.html

24. Echavarria, J. (2011). El significado de ser militar. Rumbos Aeronáuticos (24). Recuperado de http://www.eam.iua.edu. ar/rumbos/Revista-24/RevistaRumbos24-Nota05.html

25. Esteruelas, B. (9 de octubre de 2003). EE UU abre el debate sobre la toma de decisiones por consenso en la OTAN. El Pais. Recuperado de http://elpais.com/diario/2003/10/09/ internacional/1065650413_850215.html

26. García Segura, H. (6 de junio de 2013). Uribe también intentó acuerdo con la Otan. El Espectador. Recuperado de http://www.elespectador.com/noticias/politica/uribe-tambien-intento-acuerdo-otan-articulo-426125

27. Fariza, I. (2 de abril de 2014). La UE dobla su financiación a las misiones de paz en África. El País. Recuperado de http:// internacional.elpais.com/internacional/2014/04/02/actualidad/1396468012_225226.html

28. Federació d’ONG per la Pau. (2011). Campaña No a la OTAN No a la guerra [documento en línea]. Recuperado de http://www.vientosur.info/documentos/No\%20OTAN.pdf

29. Field, R. (2002). John Dewey (1859-1952). Internet Encyclopedia of Philosophy. Recuperado de http://www.iep.utm. edu/dewey/

30. Forte, D. (2007). Violaciones de derechos humanos por integrantes de las misiones de paz de la ONU. Papeles FUHEM (96), 131-141.

31. Fuentes, C. (2006). La apuesta por el "poder blando". Política exterior de la Concertación 2000-2006 [documento en línea]. Recuperado de http://www.icso.cl/wp-content/uploads/2009/11/PoliticaexteriorUDPFuentes.pdf

32. Fuerzas Armadas de Noruega. (2015). Operation Agile Genie [página web]. Recuperado de https://itjenestefornorge.no/operasjoner/operation-agile-genie

33. García, J. \& Bruzzone, E. (2012). La alianza extra OTAN de la Argentina: gestación, funcionamiento y actualidad [documento en línea]. Recuperado el 2016, de http:/www. alainet.org/es/active/57127

34. Giavendoni Pita, M. (noviembre, 2004). Argentina y su participación en operaciones de paz. VII. Encuentro Nacional de Estudios Estratégicos, Buenos Aires, Argentina. Recuperado de: http://www.ieeri.com.ar/actividades/docs/ act $\% 20-\% 20$ vii $\% 20$ encuentro\%20-\%20argentina $\% 20$ y\%20las\%20misiones $\% 20 \mathrm{de} \% 20$ paz.pdf
35. Gobierno quiere ser socio en cooperación de la OTAN (4 de junio de 2013). Revista Semana. Recuperado de http:// www.semana.com/nacion/articulo/gobierno-quiere-socio-cooperacion-otan/345329-3

36. Kamp, K.-H. (2014). La OTAN ante nuevos desafíos. Deutschland.de. Recuperado de https://www.deutschland.de/ es/topic/politica/paz-seguridad/la-otan-ante-nuevos-desafios

37. Konstantinidis, A. (11 de febrero de 2016). La OTAN participará en el Egeo en la crisis de los refugiados. El Mundo. Recuperado de http:/www.elmundo.es/internacional/2016/02/11/56bc60ad22601d027d8b464d.html

38. Lahera, E. (2005). Del dicho al hecho: ¿Cómo implementar las políticas? [documento en línea]. Recuperado de http://uca.edu.sv/mcp/media/archivo/eb4caf_comoimplementarlaspoliticaslahera.pdf

39. La monarquía que está enfurecida con Luis Fernando Velasco. (31 de marzo de 2016). Revista Semana. Recuperado de http://www.semana.com/nacion/articulo/marruecos-protesta-por-presencia-de-saharauis-en-congreso/467471

40. Las claves del acuerdo de Colombia con la OTAN. (11 de octubre de 2013). Revista Semana. Recuperado de http:// www.semana.com/nacion/articulo/las-claves-del-acuerdode-colombia-con-la-otan/357294-3

41. Le Jeune, C. (2010). New NATO Member States: The Benefits and Drawbacks of Enlargement. The Land Warfare Papers, 77, 1-22. Recuperado de https://www.ausa.org/publications/ilw/ilw_pubs/Documents/LWP\%2077_web.pdf

42. Los jefes de Estado europeos celebran los "decenios de paz" que ha traído la UE. (4 de agosto de 2014). $A B C$. Recuperado de http://www.abc.es/casa-del-rey/rey-felipe-vi/20140804/ abci-felipe-belgica-guerra-mundial-201408041658.html

43. Los talibanes se jactan de haber "derrotado" a la OTAN en Afganistán. (24 de diciembre de 2014). El País. Recuperado de http://internacional.elpais.com/internacional/2014/12/29/actualidad/1419857222_567133.html

44. Majumdar, D. (febrero 10 de 2015). Europe's 4 Deadliest Military Powers. The National Interest. Recuperado de http://www.nationalinterest.org/feature/europes-4-deadliest-military-powers-12214

45. Martín, J. J. (2010). La OTAN ante la Cumbre de Lisboa - El Nuevo Concepto Estratégico [presentación en línea]. Recuperado de http://www.ieee.es/Galerias/fichero/ JPoliticos/OTANLisboa_2010.pdf

46. Martínez, R. (19 de noviembre de 2010). La OTAN aprueba el concepto estratégico para adaptarse al siglo XXI. El País. Recuperado de http://internacional.elpais.com/internacional/2010/11/19/actualidad/1290121203_850215.html

47. Meichsner, S. (2007). El campo político en la perspectiva teórica de Bourdieu. Iberóforum. Revista de Ciencias Sociales de la Universidad Iberoamericana, 2 (3), 1-22. 
48. Minas antipersonales dejan más de 10.000 víctimas en Colombia. (22 de septiembre de 2012). El Espectador. Recuperado de http://www.elespectador.com/noticias/ judicial/minas-antipersonales-dejan-mas-de-10000-victimas-colomb-articulo-377332

49. Ministerio de Asuntos Exteriores y Cooperación de España. (2015) ¿Qué es la Alianza Atlántica, quées la OTAN? Recuperado de http://www.exteriores.gob.es/RepresentacionesPermanentes/ OTAN/es/quees2/Paginas/QueeslaOTAN.aspx

50. Ministerio de la Defensa Nacional de Guatemala. (2015). Dirección de Relaciones Civiles Militares [página web]. Recuperado de http://www.mindef.mil.gt/emdn/d5/index.html

51. Myers, D. G. (2006). El aprendizaje basado en la observación. En Autor, Psicología (pp. 336-341). Buenos Aires: Editorial Panamericana.

52. Naciones Unidas. (1945). Carta de las Naciones Unidas. Recuperado de http://www.un.org/es/documents/charter/ index.shtml

53. National Defence and the Canadian Forces. (2008). Details/ Information for Canadian Forces (CF) Operation ANCHOR GUARD. Recuperado e http://www.cmp-cpm.forces.gc.cal dhh-dhp/od-bdo/di-ri-eng.asp?IntlOpId=143\&CdnOpId $=172$

54. North Atlantic Treaty Organization (NATO). (1949). The North Atlantic Treaty (1949) [documento en línea]. Recuperado de http://www.nato.int/nato_static/assets/ pdf/stock_publications/20120822_nato_treaty_en_ light_2009.pdf

55. North Atlantic Treaty Organization (NATO). (1999). El Concepto Estratégico de la OTAN [documento en línea]. Recuperado de http://www.centredelas.org/images/stories/ adjunts/509_concepto_estrategico_1999.pdf

56. North Atlantic Treaty Organization (NATO). (2015a). Operations and missions: past and present. Recuperado de http://www.nato.int/cps/en/natohq/topics_52060.htm

57. North Atlantic Treaty Organization (NATO). (2015b). Partners. Recuperado de http://www.nato.int/cps/en/natolive/51288.htm

58. North Atlantic Treaty Organization (NATO). (2016). What is NATO?-BasicPoints(páginadeinternet).Recuperadodehttp://www. nato.int/nato-welcome/index.html?utm_medium=email\&utm_ campaign=NATO $\% 20$ Update $\% 2020168 \&$ utm_content $=$ +CID_0dc4c8b85a50a9af6bf8bc79d38b3e89\&utm_source= Email\%20marketing\%20software

59. Organisation for Economic Cooperation and Development (OECD). (2003). Glossary of Statistical Terms. Recuperado de https://stats.oecd.org/glossary/detail.asp?ID=126

60. Organización de las Naciones Unidas (ONU). (2015). Historia de las operaciones de mantenimiento de la paz.
Recuperado de http://www.un.org/es/peacekeeping/operations/history.shtml

61. OTAN descarta el ingreso de Colombia como país miembro. (3 de junio de 2013). El Tiempo. Recuperado de http:// www.eltiempo.com/archivo/documento/CMS-12842425

62. Péndola, M. (2005). Costos y beneficios de la participación de Chile en operaciones de paz. Revista de Marina, 5, 445-453.

63. Permanent Representation of France to NATO. (2013). The missions of the Alliance: NATO's Strategic Concept [documento en página web]. Recuperado de http://www. rpfrance-otan.org/The-missions-of-the-Alliance-NATO

64. Philippe Leclerc: "ACNUR propondrá la distribución de refugiados desde América Latina hasta Australia”. (3 de marzo de 2016). Euronews. Recuperado de http://es.euronews.com/2016/03/03/philippe-leclerc-acnur-propondra-la-distribucion-de-refugiados-desde-americal

65. Poor, J. (2012). Pat Buchanan: 'We should have abolished NATO'. The Daily Caller. Recuperado de http://dailycaller. com/2012/05/19/pat-buchanan-we-should-have-abolished-nato/

66. Presidencia de la República de Colombia. (2015). Importancia de la participación de Colombia en las operaciones de mantenimiento de la paz. Recuperado de http://wp.presidencia. gov.co/Noticias/2015/Septiembre/Paginas/20150927_11Importancia-de-la-participacion-de-Colombia-en-lasoperaciones-de-mantenimiento-de-la-paz.aspx

67. Ramírez, S. (7 de junio de 2013). ¿Política interna o giro internacional? El Tiempo. Recuperado de http://www.eltiempo.com/archivo/documento/CMS-12853728

68. Reino Unido enviará 70 militares a la misión de paz en Somalia. (2015). Deutsche Welle. Recuperado de http://m. dw.com/es/reino-unido-enviar\%C3\%A1-70-militares-a-la-misi\%C3\%B3n-de-paz-en-somalia/a-18745301

69. Reyes, E. \& Saiz, E. (4 de junio de 2013). La cooperación entre Colombia y la OTAN genera polémica en el ALBA. El País. Recuperado de http://internacional.elpais.com/internacional/2013/06/04/actualidad/1370366014_995050. html

70. Rodríguez, J. (20 de junio de 2016). ONU pretende atajar los escándalos de abusos sexuales de sus soldados. Hispantv. Recuperado de http://www.hispantv.com/newsdetail/reporteros/35909/onu-pretende-atajar-los-escandalos-de-abusos-sexuales-de-sus-soldados

71. Ruiz, D. (2005). El reto transformacional de Afganistán. Revista de la OTAN. Recuperado de http://www.nato.int/ docu/review/2005/issue2/spanish/art2.html

72. Sefrin, O. (24 de junio de 2009). Capacitando para la paz mundial. Deutschland.de. Recuperado de https://www. 
deutschland.de/es/topic/politica/paz-seguridad/capacitando-para-la-paz-mundial

73. Son cinco los muertos por paro armado del Clan Úsuga en noroeste colombiano. (1 de abril de 2016). El Espectador. Recuperado de http://www.elespectador.com/noticias/judicial/son-cinco-los-muertos-paro-armado-del-clan-usuga-noroes-articulo-624931

74. Spidla, V. (12 de mayo de 2004). Europa: la unión y la paz. La Nación. Recuperado http://www.lanacion.com. ar/600331-europa-la-union-y-la-paz

75. Torre, W. (10 de enero de 2015). Los pros y contras de los cascos azules. Excelsior. Recuperado de http://www.excelsior. com.mx/nacional/2015/01/10/1001883
76. Trece ańos de guerra en Afganistán. (28 de diciembre de 2014). El Pais. Recuperado de http://internacional.elpais.com/internacional/2014/12/28/actualidad/1419782490_275134. html

77. United Nations High Commissioner for Refugees (UNHCR). (1999). Kosovo Emergency [documento en línea]. Recuperado de http://www.unhcr.org/3e2d4d5f7.pdf

78. Vignolles, P. (2003). El valor de las Fuerzas Armadas como instrumento de la política exterior: Argentina en misiones de paz y coaliciones militares. Security and Defense Studies Review, 2, 143-188.

79. Vilaseca, B. (20 de enero de 2008). Aprender a través de la experiencia. El Pais. Recuperado de http://elpais.com/diario/2008/01/20/negocio/1200840454_850215.html 